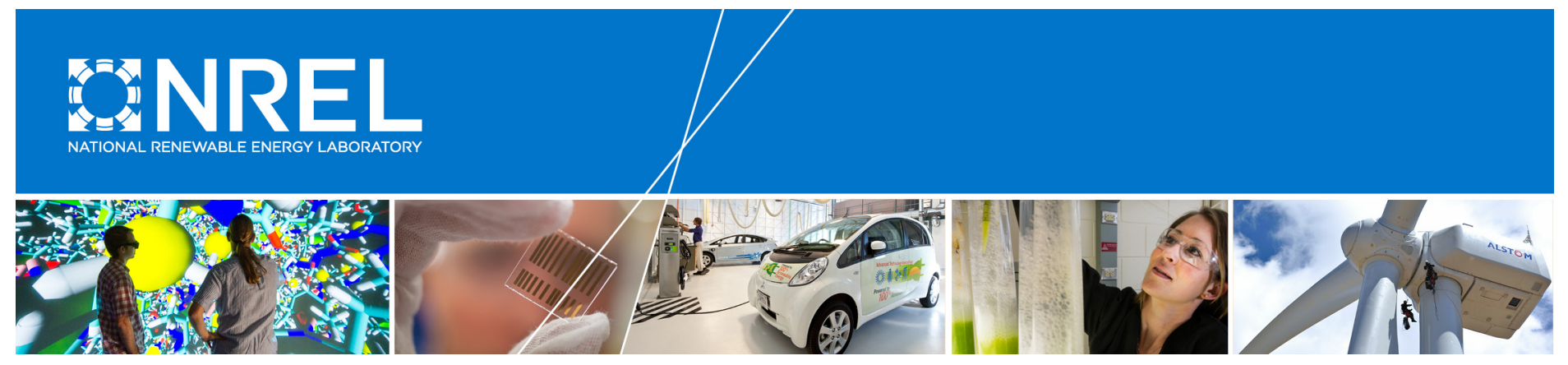

\title{
Expanding Midscale Solar: Examining the Economic Potential, Barriers, and Opportunities at Offices, Hotels, Warehouses, and Universities
}

Lori Bird, Pieter Gagnon, and Jenny Heeter National Renewable Energy Laboratory

NREL is a national laboratory of the U.S. Department of Energy Office of Energy Efficiency \& Renewable Energy Operated by the Alliance for Sustainable Energy, LLC

This report is available at no cost from the National Renewable Energy Laboratory (NREL) at www.nrel.gov/publications.

Technical Report

NREL/TP-6A20-65938

September 2016 
Expanding Midscale Solar: Examining the Economic Potential, Barriers, and Opportunities at Offices, Hotels, Warehouses, and Universities

Lori Bird, Pieter Gagnon, and Jenny Heeter National Renewable Energy Laboratory

Prepared under Task No. ST6B.0231
NREL is a national laboratory of the U.S. Department of Energy Office of Energy Efficiency \& Renewable Energy Operated by the Alliance for Sustainable Energy, LLC

This report is available at no cost from the National Renewable Energy Laboratory (NREL) at www.nrel.gov/publications.

Technical Report (Arial 10 pt Bold)

NREL/TP-6A20-65938

September 2016

Contract No. DE-AC36-08G028308
National Renewable Energy Laboratory 15013 Denver West Parkway 303-275-3000 • www.nrel.gov 


\section{NOTICE}

This report was prepared as an account of work sponsored by an agency of the United States government. Neither the United States government nor any agency thereof, nor any of their employees, makes any warranty, express or implied, or assumes any legal liability or responsibility for the accuracy, completeness, or usefulness of any information, apparatus, product, or process disclosed, or represents that its use would not infringe privately owned rights. Reference herein to any specific commercial product, process, or service by trade name, trademark, manufacturer, or otherwise does not necessarily constitute or imply its endorsement, recommendation, or favoring by the United States government or any agency thereof. The views and opinions of authors expressed herein do not necessarily state or reflect those of the United States government or any agency thereof.

This report is available at no cost from the National Renewable Energy Laboratory (NREL) at www.nrel.gov/publications.

Available electronically at SciTech Connect http:/www.osti.gov/scitech

Available for a processing fee to U.S. Department of Energy and its contractors, in paper, from:

U.S. Department of Energy

Office of Scientific and Technical Information

P.O. Box 62

Oak Ridge, TN 37831-0062

OSTI http://www.osti.gov

Phone: 865.576.8401

Fax: 865.576.5728

Email: reports@osti.gov

Available for sale to the public, in paper, from:

U.S. Department of Commerce

National Technical Information Service

5301 Shawnee Road

Alexandria, VA 22312

NTIS http://www.ntis.gov

Phone: 800.553 .6847 or 703.605 .6000

Fax: 703.605.6900

Email: orders@ntis.gov 


\section{Acknowledgments}

This work was funded by the U.S. Department of Energy's (DOE's) Office of Energy Efficiency and Renewable Energy. The authors thank the Solar Energy Technologies Office for its support of this work. In particular, the authors thank Dan Boff, Angela Crooks, and Odette Mucha of DOE for their support.

For their thoughtful review of the document, the authors thank Ben Margolis, Sol Systems; Carolyn Pino, SunStreet; Dan Boff, DOE; and Paul Schwab and Jeffrey Logan, NREL. We would also like to thank the following individuals for participating in market interviews: Phil Armstrong, juwi; Jeff Bedard, NREL; Ryan Economy, BayWa r.e.; Frank Lyman, McCauley Lyman LLC; Ben Margolis, Sol Systems; Lars Norell, Altus Power; Kate Sherwood, SolarCity; Josh Sturtevant, Sullivan \& Worcester LLP; Kirby Brendsel, Westin; Thomas Webster, Hilton; Shea Jameel, Starwood Hotels.

This work was supported by the U.S. Department of Energy under Contract No. DE-AC3608GO28308 with the National Renewable Energy Laboratory. 


\section{Acronyms and Abbreviations}

AASHE

DOE

EIA

EPA

FIT

ITC

LEED

NREL

NYPA

PACE

PPA

PTO

PV

REC

REIT

RFP

SAM

SEIA

URDB
Association for Advancement of Sustainability in Higher Education

U.S. Department of Energy

U.S. Energy Information Agency

U.S. Environmental Protection Agency

feed-in tariff

investment tax credit

Leadership in Energy \& Environmental Design

National Renewable Energy Laboratory

New York Power Authority

property-assessed clean energy

power purchase agreement

permission to operate

photovoltaics

renewable energy certificates

real estate investment trust

request for proposal

System Advisor Model

Solar Energy Industries Association

Utility Rate Database 


\section{Executive Summary}

The midscale market for solar photovoltaics (PV), defined as behind-the-meter systems between $100 \mathrm{~kW}$ and $2 \mathrm{MW}$, has grown more slowly than other PV market segments in recent years. Cumulatively, of the nearly $26 \mathrm{GW}$ of collectively installed PV capacity, non-residential systems represent only $6.2 \mathrm{GW}-24 \%$ of the total. A number of key barriers have impeded growth, including tenant and landlord split incentives, contracting challenges, the mismatch in building lease and PV financing terms, and high transaction costs relative to project sizes.

This report explores prospects for expansion of the midscale solar market, with a focus on four building segments: offices, hotels, warehouses, and universities. These building segments were selected based on their ability to deploy solar if key barriers were removed or mitigated.

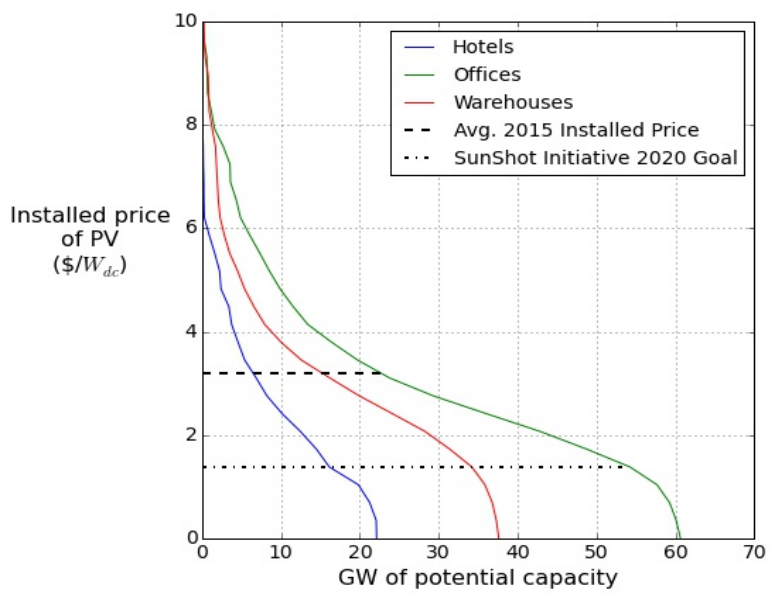

Figure ES-1. National PV demand curves for offices, hotels, and warehouses

At 2015 average $(50-100 \mathrm{~kW})$ installed prices $\left(\$ 3.20 / \mathrm{W}_{\mathrm{DC}}\right)$, the techno-economic potential for these building segments is substantial, at $44 \mathrm{GW}$ (Figure ES - 1), with approximately half of that capacity coming from offices $(22 \mathrm{GW})$. With further price declines on par with the with the U.S. Department of Energy's (DOE's) SunShot Initiative's 2020 targets, the techno-economic potential for these three segments could reach more than $100 \mathrm{GW}$. Techno-economic potential is an estimate of the total capacity that exists where system owners would break even on an investment in PV over the lifetime of the system. ${ }^{1}$ These estimates are derived from a new analysis that takes into account $\operatorname{lidar}^{2}$ data, building type counts, simulated load profiles, and utility rates from the Utility Rate Database (URDB). ${ }^{3}$

This analysis shows the following average trends for the four midscale solar segments examined in this report. However, findings for individual buildings in these segments may differ, given that the local retail rate structure is one of the most important drivers of the value of PV.

\footnotetext{
${ }^{1}$ The analysis assesses siting restrictions associated with roof area, shading, and other characteristics, but does not consider the age of the roof, institutional or financing barriers, or the structural ability of the building to accommodate PV.

${ }^{2}$ Lidar is a geographic surveying technology that works on the same principal as radar, except it images surfaces using light instead of sound. The data is used here to determine the suitability of rooftops for hosting PV systems.

${ }^{3}$ The Utility Rate Database provides rate structure information for more than 3,700 U.S. utilities. The database is available at http://en.openei.org/wiki/Utility_Rate_Database.
} 


\section{Offices}

- Offices have a techno-economic potential of $22 \mathrm{GW}$ at 2015 average installed prices and 54 GW at DOE's SunShot 2020 targets.

- Peak demand typically occurs during daylight hours, providing the opportunity to reduce demand charges.

- Enabling aggregate purchases by multiple tenants or subscribing to power purchase agreements (PPAs) from an offsite PV array could minimize transaction costs.

\section{Hotels}

- Hotels have a techno-economic potential of $6 \mathrm{GW}$ at 2015 average installed prices and $16 \mathrm{GW}$ at DOE's SunShot 2020 targets.

- Peak demand can often occur outside of daylight hours, where PV has no ability to reduce demand charges.

- While hotels often only have one tenant, financing can be more complicated due to complex franchise structures.

- Because hotels are consumer-facing, they can directly market their sustainability efforts more than offices and warehouses.

\section{Warehouses}

- Warehouses have a techno-economic potential of $15 \mathrm{GW}$ at 2015 average installed prices and $34 \mathrm{GW}$ at DOE's SunShot 2020 targets.

- Warehouses often have large unobstructed roofs that offer significant potential, but they otherwise have bill savings capabilities on the same order as offices.

- Minimizing transactions and developing solutions to the tenant/landlord split incentives, similar to offices, could help move the segment.

\section{Universities}

- A different methodology was used to estimate market potential for universities because of differences in available data. We estimate that if all universities deployed enough distributed $\mathrm{PV}$ to generate $25 \%$ of their annual electricity consumption, the total capacity would be slightly more than $16 \mathrm{GW}$. Much of this capacity would have a relatively low value compared to the aforementioned sectors, but $3.7 \mathrm{GW}$ of the capacity would be "high value"-capacity whose average bill savings would exceed $10 \phi / \mathrm{kWh}$ of electricity generated.

- In general, universities have potential to significantly expand their use of PV because of their large techno-economic potential, strong interest in sustainability, and land availability. However, a key challenge is educating decision makers about solar financing and contracting processes.

To realize substantial growth in the midscale sector in coming years, a number of strategies could be pursued to address key barriers. Based in part on discussions with market participants, options for facilitating increased deployment in the midscale market include: wider adoption of property-assessed clean energy (PACE) financing, virtual net metering, policies enabling use of third-party PPA financing, targeted educational efforts in promising market segments, and efforts to reduce transactional costs (i.e., simplifying interconnection, standardized contracts). 


\section{Table of Contents}

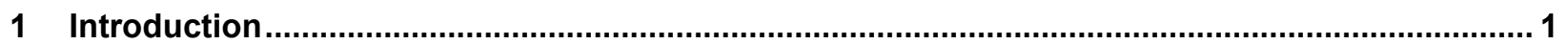

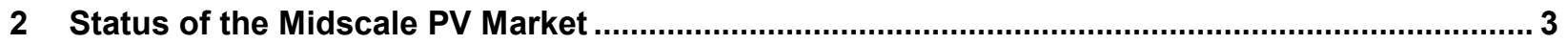

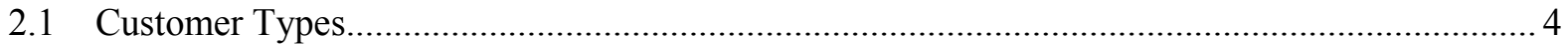

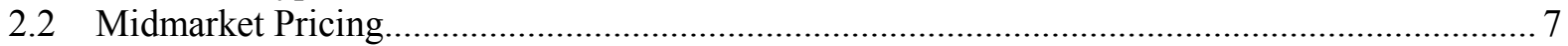

3 Technical and Economic Potential for Midscale PV Market Sectors .......................................... 8

3.1 National Technical and Economic Potentials on Offices, Hotels, and Warehouses .................... 8

3.2 National Technical and Economic Potential on Universities ................................................... 10

3.2.1 National Demand Curve for Behind-the-Meter PV on Individual Universities ............. 11

3.3 Demand Curve Methodology for Offices, Hotels, and Warehouses ......................................... 12

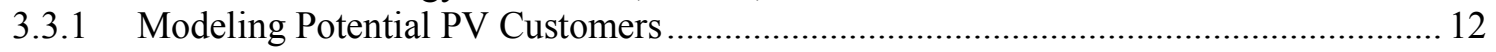

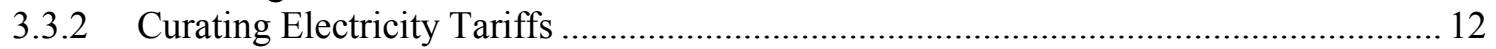

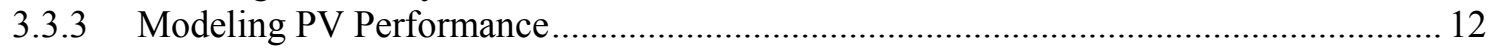

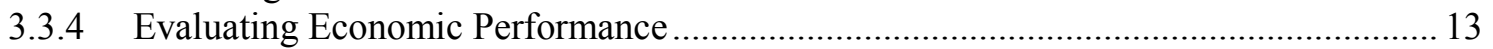

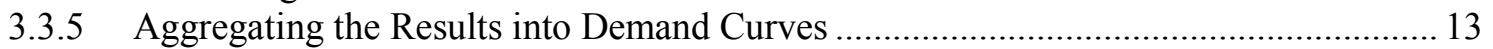

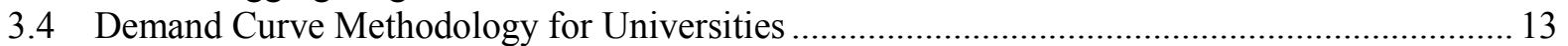

3.4.1 Constructing Individual Demand Curves for a Set of Universities .............................. 13

3.4.2 Calculating a Normalized Demand Curve for Universities........................................... 14

3.4.3 Calculating a National Demand Curve for Universities............................................... 14

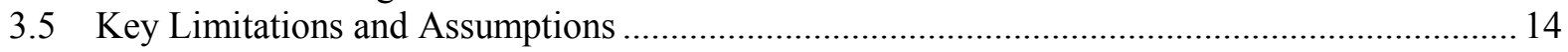

4 Opportunities and Barriers to Midscale PV Market Deployment............................................... 16

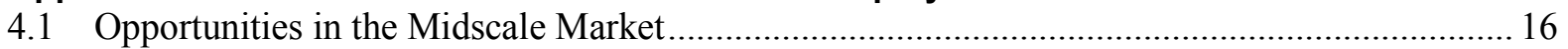

4.2 Barriers to Deployment in the Midscale Market ................................................................. 17

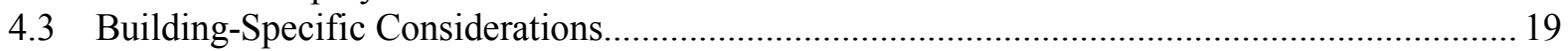

4.3.1 Electric Bill Reduction from PV on Commercial Buildings ....................................... 20

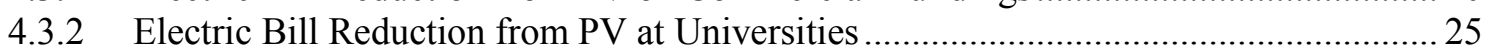

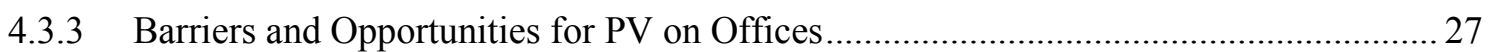

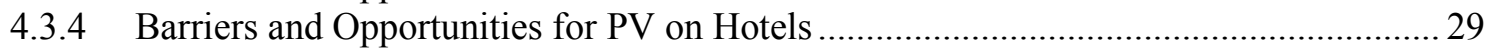

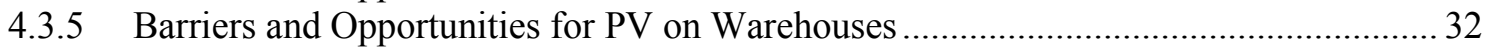

4.3.6 Barriers and Opportunities for PV at Universities .................................................... 33

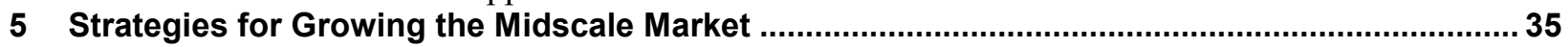

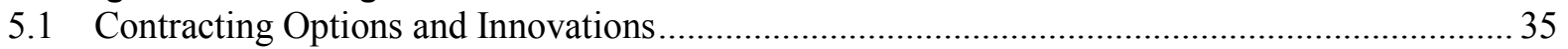

5.2 Alternative Financing Mechanisms for Midscale Market (PACE and FITs) .............................. 36

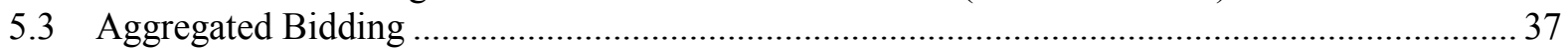

5.4 Expansion of Access to PPA Options .................................................................................... 38

5.5 Increased Metering and Locational Siting Flexibility (Virtual Net Metering and Community

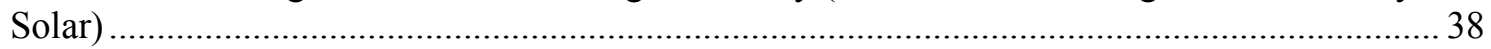

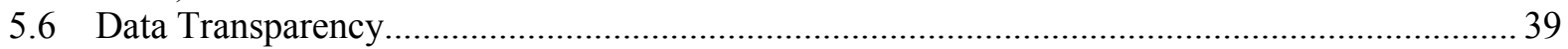

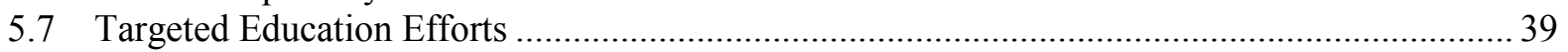

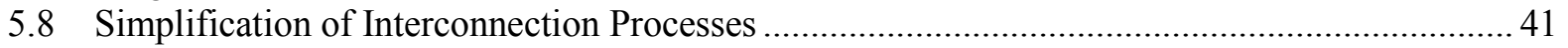

5.9 Simplification and Standardization of Transactions........................................................... 42

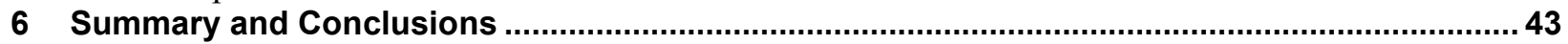

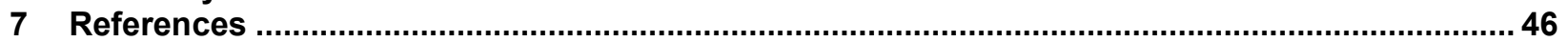




\section{List of Figures}

Figure ES-1. National PV demand curves for offices, hotels, and warehouses ...................................... V Figure 1. Cumulative capacity of small, midscale, and large installations in the Tracking the Sun data set 3 Figure 2. Comparison of cumulative capacity in Tracking the Sun versus SEIA/GTM ........................... 4 Figure 3. Share of non-residential installations in Arizona, California, New York, Massachusetts, and

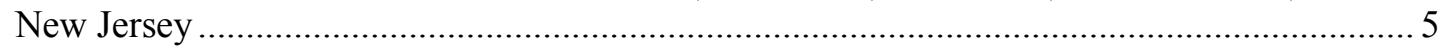

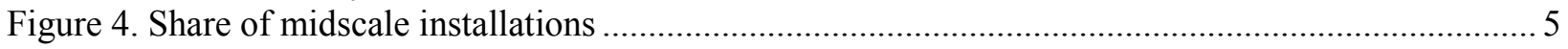

Figure 5. Share of onsite solar by participants in EPA's Green Power Partnership ................................ 6

Figure 6. Monthly mean prices by market, 2004-2016 ............................................................... 7

Figure 7. National demand curves for rooftop PV on offices, hotels, and warehouses ............................9

Figure 8. First year bill saving demand curves for offices, hotels, and warehouses ............................... 10

Figure 9. National demand curve for behind-the-meter PV on universities .......................................... 11

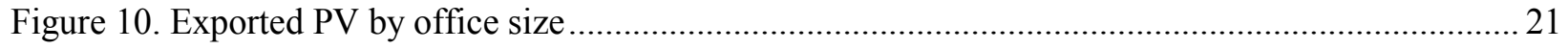

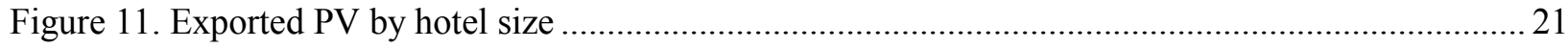

Figure 12. Exported PV for warehouses ........................................................................................ 22

Figure 13. Example of influence of increasing quantities of PV on October's monthly max demand for a

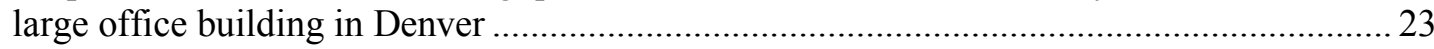

Figure 14. Example of influence of increasing quantities of PV on October's monthly max demand for a

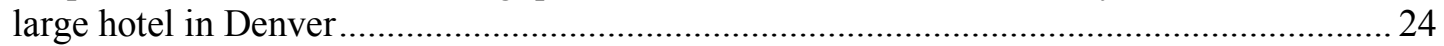

Figure 15. Example of influence of PV on October's monthly max demand of a warehouse in Denver... 25

Figure 16. First year electriciy bill savings for seven universities...................................................... 26

Figure 17. Average PV generation value by system size and fraction of total electriciy consumption for

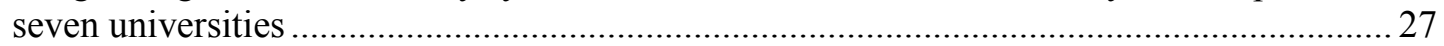

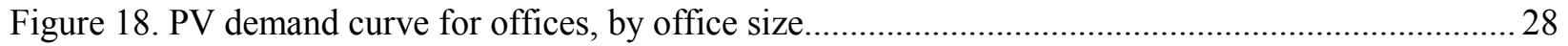

Figure 19. PV demand curve for hotels, by hotel size ....................................................................... 30

Figure 20. PV demand curve for warehouses, by warehouse size …...................................................... 32

\section{List of Tables}

Table 1. Technical Assumptions used in Demand Curve Generation................................................... 14

Table 2. Financial Assumptions used in Demand Curve Generation ................................................... 15

Table 3. Selected Sustainability Associations for Building Segments................................................... 40

Table 4. Comparison of Opportunities for PV Deployment by Market Segment......................................4 44 


\section{Introduction}

The midscale solar market—loosely defined as behind-the-meter systems between $100 \mathrm{~kW}$ and 2 MW - has grown more slowly than the residential and utility-scale market segments in recent years. While data on installations in the midscale market, or midmarket, specifically are not available, the Solar Energy Industries Association (SEIA)/GTM Research data on non-residential installations ${ }^{4}$ shed light on the trends in this sector. In 2015, non-residential solar photovoltaic (PV) projects represented only $14 \%$ of the total installed PV capacity in that year and megawatts installed in the non-residential sector have been stagnant for the past three years (SEIA/GTM 2016). Cumulatively, of the nearly $26 \mathrm{GW}$ of collectively installed PV capacity, non-residential systems represent only $6.2 \mathrm{GW}-24 \%$ of the total. A recent analysis of lidar data estimated there is the potential for $232 \mathrm{GW}$ of PV capacity on large buildings in the United States, showing a significant untapped market for midscale solar (Gagnon et al. 2016). ${ }^{5}$ The midscale solar market has many barriers, including landlord and tenant split incentives, site restrictions, financing challenges, and high transaction costs that make the economics less attractive than for larger system systems.

This paper explores the potential for expansion of the midscale solar market by considering the economic potential for PV adoption as well as the barriers to and opportunities for PV deployment. In this analysis, we focus on four building segments: offices, hotels, warehouses, and universities. ${ }^{6}$ These segments were selected based on their ability to deploy solar if key barriers were removed or mitigated. For each of our four segments, we explore key barriers (e.g., tenant and landlord issues, contracting challenges, transaction costs) and opportunities (e.g., favorable economics, potential for demand charge savings, interest in achieving sustainability goals), based on economic analysis of building loads and rates and interviews with key stakeholders, including installers, financiers, and representatives in these segments. Earlier studies also examined the challenges and potential solutions for installing solar PV on leased buildings and the hospitality sector (Navigant Consulting 2015a; Navigant Consulting 2015b).

In this analysis, we also estimate the economic potential for PV deployment in each of these four building segments. The analysis uses new methods to generate a demand curve to show the breakeven price of solar in each segment, up to the maximum that the building segment can support. ${ }^{7}$ We build our model of economic potential using lidar data, building type counts, simulated load profiles, and utility rates from the Utility Rate Database (URDB). ${ }^{8}$ This work builds on earlier National Renewable Energy Laboratory (NREL) analyses of the technical potential for PV adoption and breakeven analysis in commercial buildings (Gagnon et al. 2016; Davidson et al. 2015; Chung et al. 2015).

\footnotetext{
${ }^{4}$ SEIA/GTM defines "non-residential" as installations where the off-taker is neither a homeowner nor a utility.

${ }^{5}$ Large buildings were defined as having a footprint that exceeded $25,000 \mathrm{ft}^{2}$. Assuming a module power density of $160 \mathrm{~W} / \mathrm{m}^{2}$, ground coverage ratio of 0.7 , and taking into consideration the typical fraction of roof area suitable for PV deployment, a typical $25,000 \mathrm{ft}^{2}$ roof could host up to approximately $150 \mathrm{~kW}$ of PV.

${ }^{6}$ We use the term "university" to refer to the larger higher education sector.

${ }^{7}$ The demand curves consider both the potential capacity that could be built based on the building structure and local solar resource as well as the economics of the system in light of electricity consumption patterns of the host building and utility electricity tariffs.

${ }^{8}$ The Utility Rate Database provides rate structure information for more than 3,700 U.S. utilities. The database is available at http://en.openei.org/wiki/Utility Rate Database.
} 
In the first section of this paper, we explore available data on PV installation trends to better understand PV adoption patterns in the four market segments on which we are focusing: offices, hotels, warehouses, and universities. Then, we explore the economic potential for PV adoption in each of these market segments in the United States. Next, we discuss key barriers to adoption to date, some of which are common across market segments, as well as opportunities for accelerated PV adoption based on interviews and feedback from industry participants. Finally, we conclude with a discussion of steps that could be taken to reduce barriers to adoption and enable accelerated adoption of PV in the segments examined. 


\section{Status of the Midscale PV Market}

There are many ways to slice the "midscale" solar market. Because one comprehensive data set on the midscale PV market does not exist, we present a snapshot of available data in this section.

For a high-end estimate of the midscale market, we use SEIA/GTM's non-residential category, which is defined by the off-taker. Systems in which the off-taker is not a homeowner or a utility are by default defined as "non-residential." In 2015, the non-residential market totaled 6,100 MW (24\%) of capacity, compared to 5,600 MW in the residential sector and 13,900 MW in the utility sector (SEIA/GTM 2016).

Data are also available from the Tracking the Sun report (Barbose and Darghouth 2016), which reports solar PV system and price data derived from state and utility incentive programs, solar renewable energy credit registration systems, and interconnection programs. The data represent more than $80 \%$ of the residential and non-residential markets to date and cover the entire residential sector and all non-residential roof-mounted systems as well as non-residential ground mounted systems up to $5 \mathrm{MW}_{\mathrm{AC}}$. Tracking the Sun data are available by system size. Using a midscale market definition of $100 \mathrm{~kW}$ to $2 \mathrm{MW}$, data show 3,300 MW of midscale cumulative PV capacity installed by 2015 , representing $34 \%$ of installed residential and non-residential capacity defined in the Tracking the Sun data set (Figure 1).

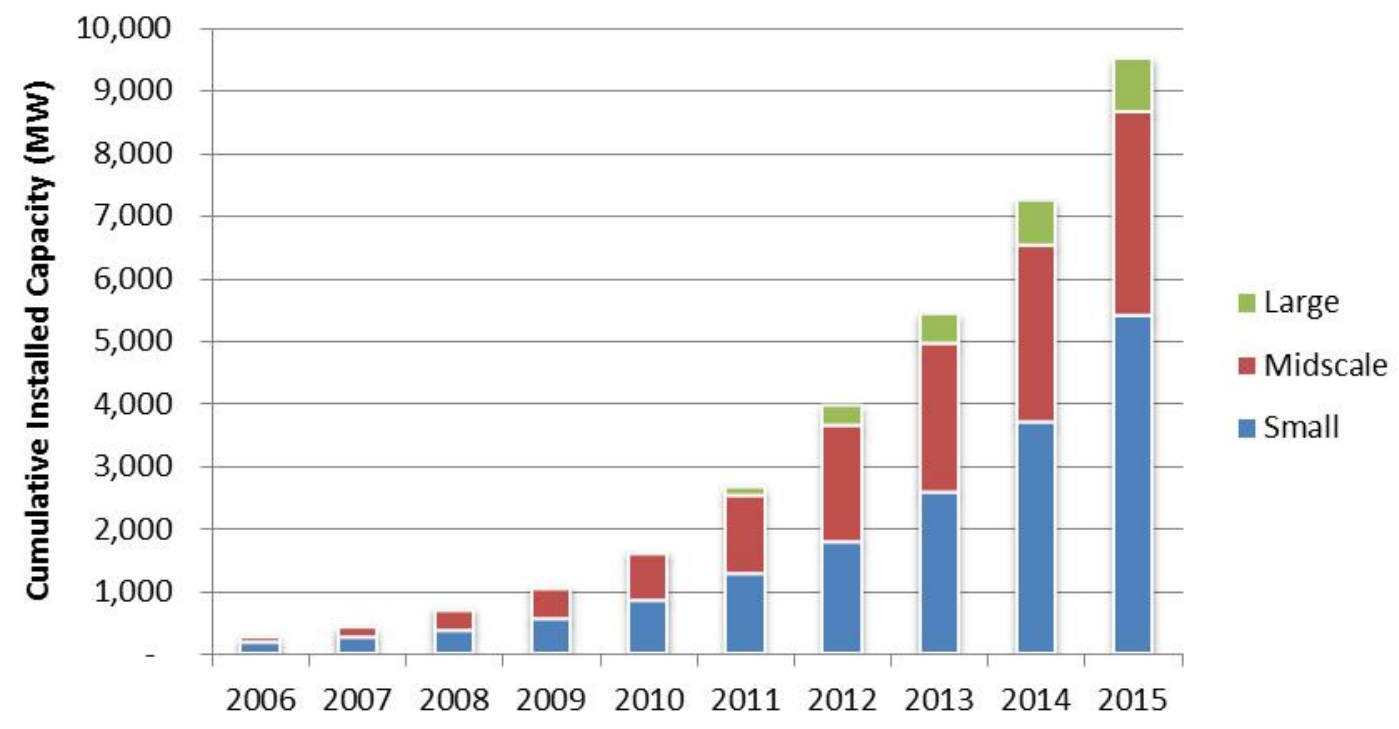

Figure 1. Cumulative capacity of small, midscale, and large installations in the Tracking the Sun data set

Data are sourced from Tracking the Sun (Barbose and Darghouth 2016).

This midscale market estimate is smaller than GTM's non-residential estimate because it includes a more limited set of project sizes and draws from a smaller data set of PV installations (Figure 2). Both data sets are presented in order to give the most comprehensive picture of midscale solar. 


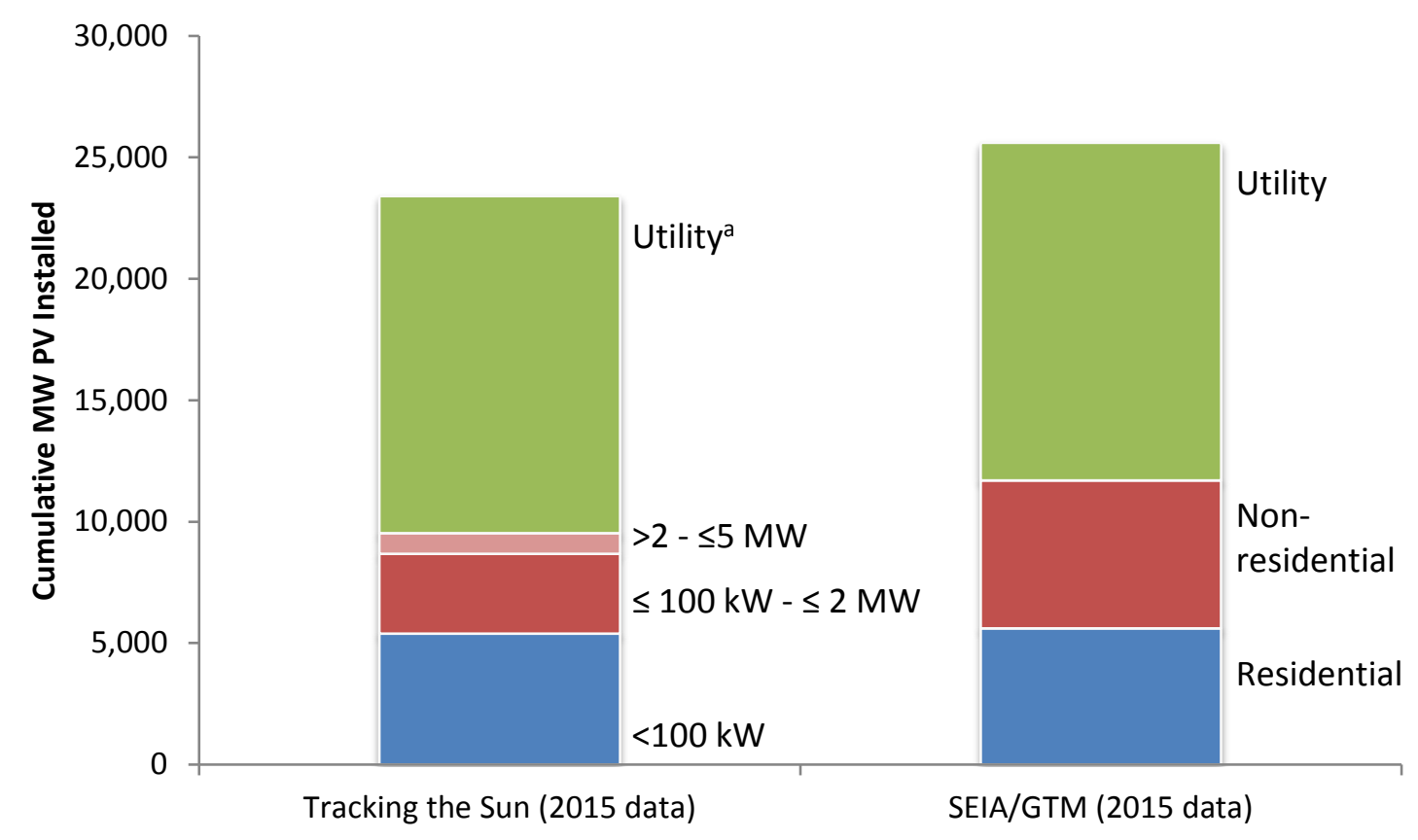

Figure 2. Comparison of cumulative capacity in Tracking the Sun versus SEIA/GTM

a Utility scale cumulative installation are from Bolinger and Seel 2016.

\subsection{Customer Types}

Some additional state data are available from GTM on the customer types in the non-residential market. Looking at data from Arizona, California, New York, Massachusetts, and New Jersey, GTM found that the breakdown of whether a project was either commercial and industrial, or included in the school, government, and nonprofit category was highly dependent upon the state, as a result of how incentive programs are structured (SEIA/GTM 2015). In 2014, school, government, and non-profit installations represented $42 \%$ of non-residential installations in these states (Figure 3). In Arizona and California, non-residential installations were concentrated in the school, government, and nonprofit sector. The California Solar Initiative (CSI) provided a higher incentive for government and nonprofits than for commercial systems. ${ }^{9}$ However, in New York, commercial and industrial installations represented the vast majority (84\%) of non-residential installations in 2014 (Figure 3).

\footnotetext{
${ }^{9}$ CSI's performance-based incentives for government/nonprofits ranged from $6-11 ф / \mathrm{kWh}$ greater than commercial incentives over the course of the CSI program.
} 

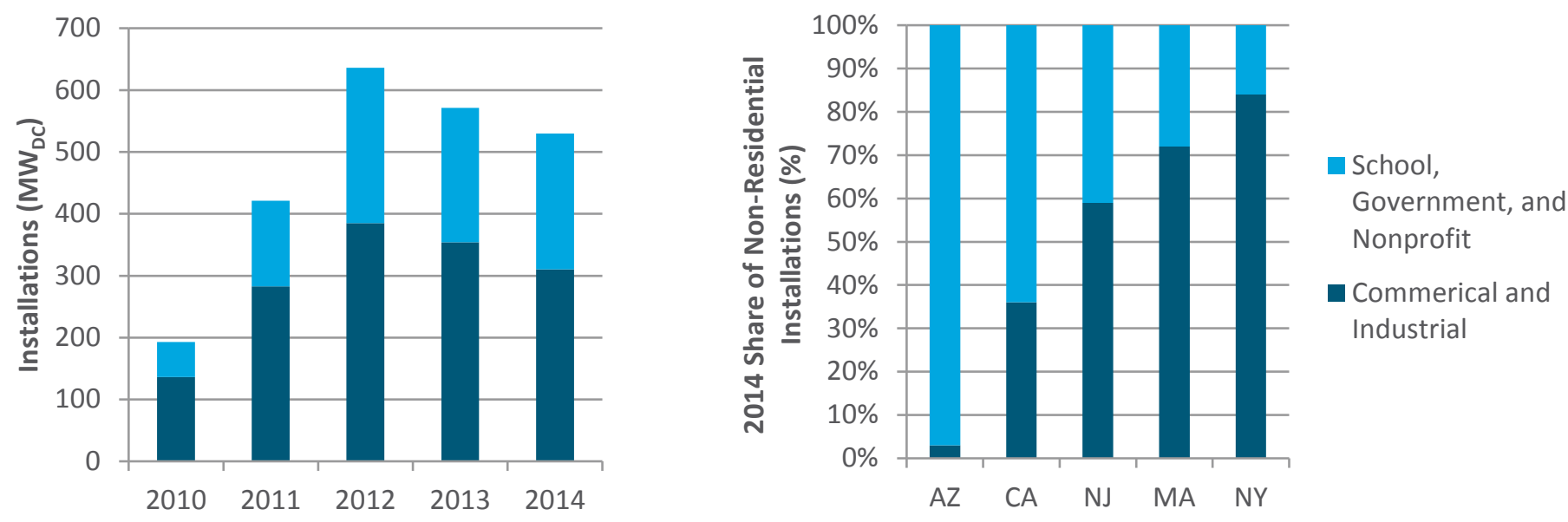

Figure 3. Share of non-residential installations in Arizona, California, New York, Massachusetts, and New Jersey

Source: SEIA/GTM 2015

About 50\% of midmarket projects in the Tracking the Sun data were classified as "commercial," followed by government (21\%) (Figure 4). About $8 \%$ of the midmarket projects are "school" projects, which are not further broken down into higher education projects. School projects tend to be slightly smaller than other midmarket projects; about $313 \mathrm{~kW}$ on average, compared to about $383 \mathrm{~kW}$ for other midmarket projects. School projects are also less likely to be groundmounted; about $86 \%$ of school projects are rooftop, compared to about $70 \%$ of other midmarket projects.

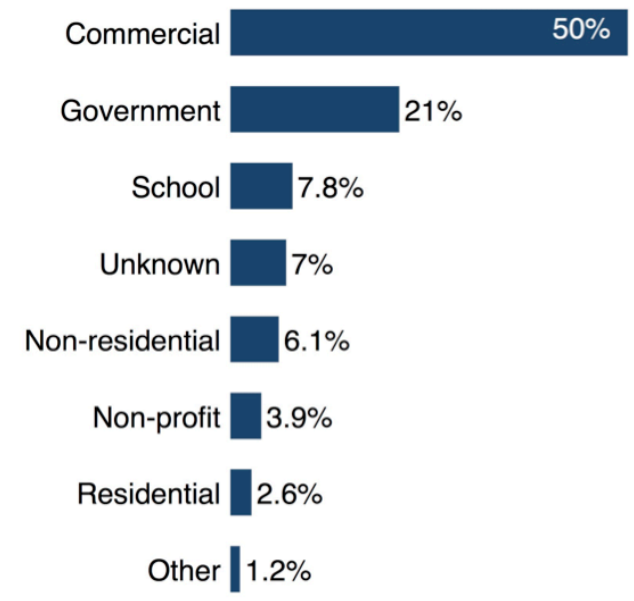

Figure 4. Share of midscale installations

Data are sourced from Tracking the Sun (Barbose and Darghouth 2016).

Data represent system sizes of $100 \mathrm{~kW}-2 \mathrm{MW}$; residential systems may represent multi-unit housing applications or potentially are misclassified.

The U.S. Environmental Protection Agency (EPA) also tracks solar installations for the institutions that participate in its Green Power Partnership program, which is a voluntary 
program of green power purchasers that currently has more than 1,300 participants using more than 30 million MWh annually of renewable energy, including solar. Of the participants in EPA's Green Power Partnership, the largest sectors with onsite solar in 2015 were retailers, technology and telecom companies, and local governments (Figure 5). Importantly, the EPA's Green Power Partnership includes only onsite solar projects where the renewable energy certificates (RECs) have been retained by the purchaser, so not all installed PV is counted in these estimates.

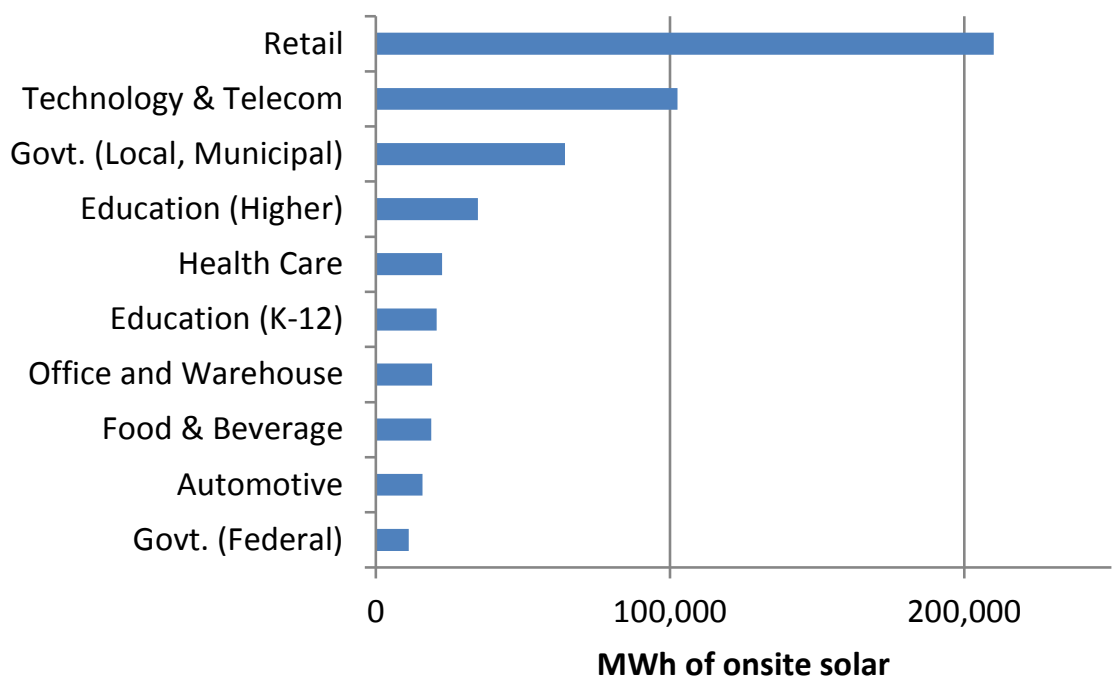

Figure 5. Share of onsite solar by participants in EPA's Green Power Partnership

Source: EPA 2015

Data on the four building types we evaluate (offices, hotels, warehouses, university campuses) are more limited. Some data are available for offices, warehouses, and universities, but there is no current data source for PV installed at hotels. SEIA's Solar Means Business (SEIA 2015) report, ${ }^{10}$ which documents commercial PV systems installed by corporations, included 92 systems on offices and corporate campuses totaling $72 \mathrm{MW}$, with an average system size of 782 $\mathrm{kW}$. The report also documented $131 \mathrm{PV}$ systems on distribution centers and warehouses totaling $196 \mathrm{MW}$, with an average system size nearly double that for offices and corporate campuses, at $1.5 \mathrm{MW}$.

Universities self-report data on installed PV systems to the Association for Advancement of Sustainability in Higher Education (AASHE). According to the AASHE data, universities and colleges had installed more than $250 \mathrm{MW}$ of solar as of August 2016, although the self-reported data cannot be considered comprehensive. Of the total reported, there were 584 installations on 333 campuses in 46 states and Washington, D.C., with an average capacity installed of $386 \mathrm{~kW}$. These figures include all installations at universities; when limiting installations to only $100 \mathrm{~kW}$ and up, there are $212 \mathrm{MW}$ in 26 states and Washington, D.C., but only 225 projects.

\footnotetext{
${ }^{10}$ SEIA's data set draws from voluntary responses by Fortune 100 companies, additional businesses known to have significant installed solar capacity, and public databases.
} 


\subsection{Midmarket Pricing}

Information on installed PV system prices in the midmarket segment is available from both SEIA/GTM and Tracking the Sun. According to modeling by SEIA/GTM, U.S. average PV system pricing in the non-residential sector has trended downward from $\$ 2.27 / \mathrm{W}_{\mathrm{DC}}$ in Q3 2014 to $\$ 2.07 / \mathrm{W}_{\mathrm{DC}}$ in Q3 2015 (SEIA/GTM 2015). GTM also provides data from state incentive program; in those cases, pricing ranged from as low as $\$ 1.81 / \mathrm{W}_{\mathrm{DC}}$ (Texas) to $\$ 5.20 / \mathrm{W}_{\mathrm{DC}}$ (Minnesota). Minnesota, Washington, and Wisconsin saw higher prices due to their low volumes and incentive program limits on the size of commercial projects (SEIA/GTM 2015).

Using Tracking the Sun data, midmarket prices follow the same trends as the rest of the DG market, falling between average prices for small and large projects. The mean midmarket price was about $28 \%$ lower $(\$ 1.28 / \mathrm{W})$ than the average small project and about $14 \%$ higher $(41 \phi / \mathrm{W})$ than the average large project in 2015 (Figure 6).

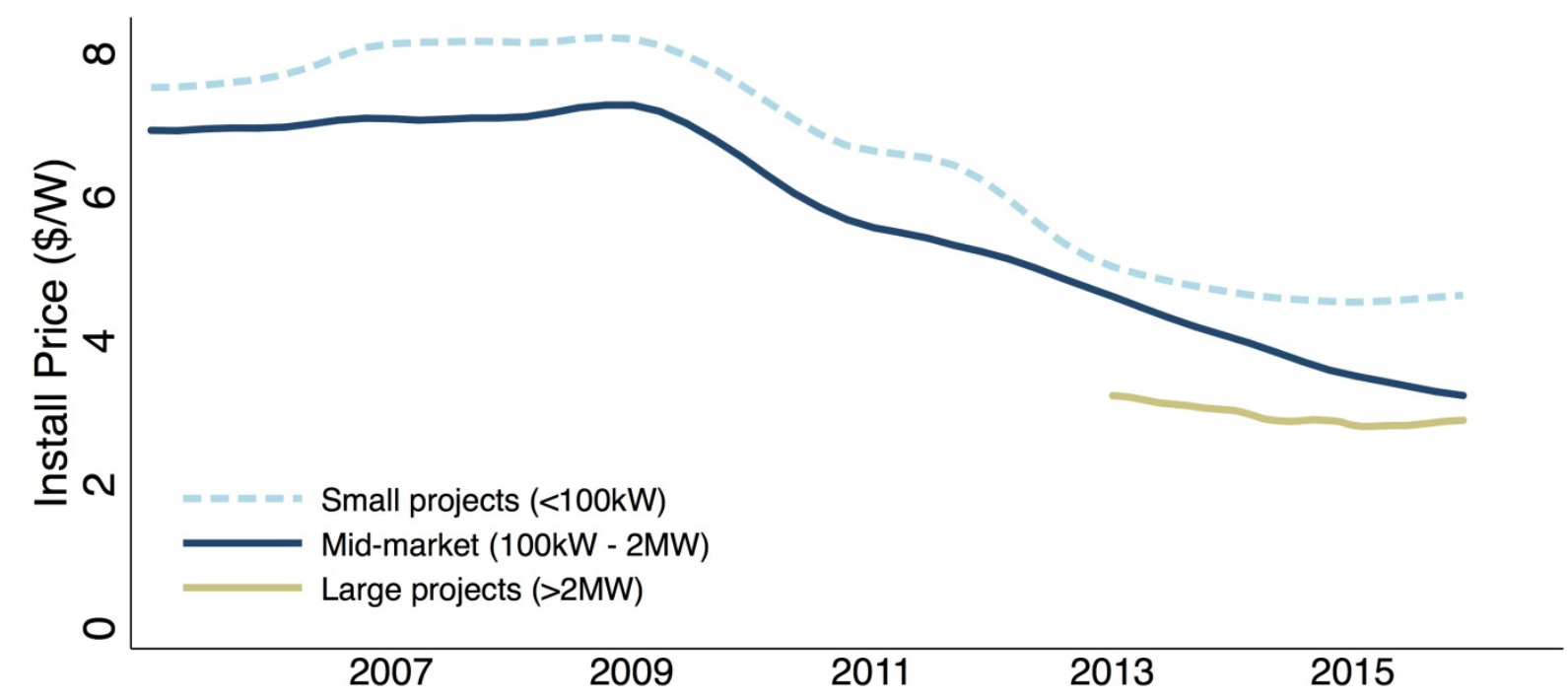

Figure 6. Monthly mean prices by market, 2004-2016

Data are sourced from Tracking the Sun (Barbose and Darghouth 2016).

Large projects are excluded until 2013 due to the very low number of such projects installed before 2013. 


\section{Technical and Economic Potential for Midscale PV Market Sectors}

This section presents estimates of the techno-economic potential for PV on the four building segments that are the focus of this analysis: offices, hotels, warehouses, and universities. These sectors were selected based on a number of criteria, including: availability of building data, expected time to deploy solar, ability of stakeholders to assist in dissemination of educational and other materials, and public benefits of deployment in the market segment.

The estimates are based on demand curves derived for each building class, which characterize the amount of PV that customers in each building sector would be interested in purchasing as a function of the installed system price.

The demand curves consider both the potential capacity that could be built based on the building structure and local solar resource as well as the economics of the system in light of electricity consumption patterns of the host building and utility electricity tariffs. In this way, the demand curves indicate how much capacity could be built that would achieve a certain level of economic performance. The technical potential for PV installations on offices, hotels, and warehouses is based on their available roof space (see Section 3.1), while a modified approach is used for universities because of their larger land area and ability to site PV in other areas within the campus and other differences described below (see Section 3.2).

\subsection{National Technical and Economic Potentials on Offices, Hotels, and Warehouses}

The technical potential of each building class, which is the upper limit on the capacity that could be installed regardless of price, is $61 \mathrm{GW}$ of PV on offices, $22 \mathrm{GW}$ on hotels, and $37 \mathrm{GW}$ on warehouses (Figure 7) ${ }^{11}$ Technical potential corresponds to the left most point of each of the curves - the quantity of capacity that would break even if the installed price were zero.

\footnotetext{
${ }^{11}$ These curves are derived from the simulation of over 40,000 representative buildings, with characteristics and frequencies informed by the Commercial Building Energy Consumption Survey, lidar analysis of rooftop trends, over 3,000 commercial electricity tariffs, and PV performance modeling. See Section 3.3 for details on the methodology.
} 


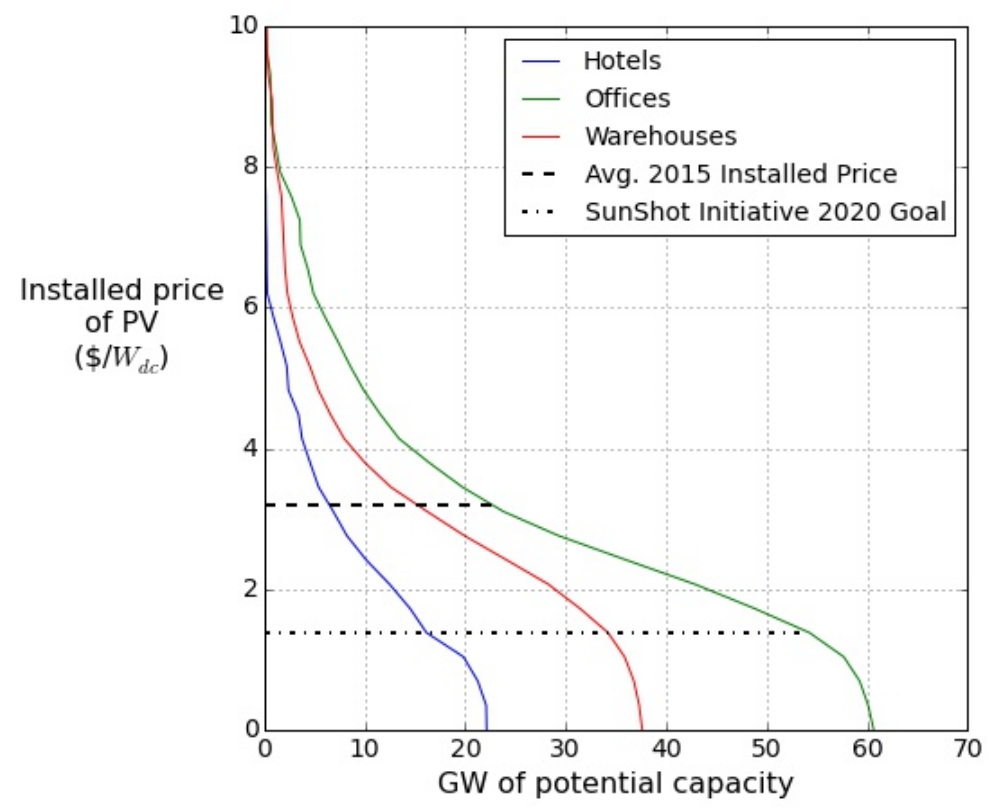

Figure 7. National demand curves for rooftop PV on offices, hotels, and warehouses

Figure 7 shows the quantity of PV capacity that would exactly break even-meaning the present value of the discounted profits would equal the present value of the discounted costs - as a function of the installed price. ${ }^{12}$ For instance, the average price of PV for non-residential systems between 50 and $100 \mathrm{~kW}$ installed in 2015 was $\$ 3.20 / \mathrm{W}_{\mathrm{DC}}$ (Barbose and Darghouth 2016). At this price, $22 \mathrm{GW}$ of PV would break even on offices, $15 \mathrm{GW}$ on warehouses, and $6 \mathrm{GW}$ on hotels. Therefore, at this price, the percent of the total technical potential that would break even is $37 \%$ for offices, $41 \%$ for warehouses, and 30\% for hotels. If installed PV prices were to continue to fall while electricity prices remained constant, the amount of PV capacity that would break even would increase substantially. For example, at DOE's SunShot Initiative's installed price target for 2020 of $\$ 1.38 / \mathrm{W}_{\mathrm{DC}}{ }^{13}$ and at current electricity prices, $16 \mathrm{GW}$ of capacity on hotels would break even, $34 \mathrm{GW}$ on warehouses, and $54 \mathrm{GW}$ on offices. ${ }^{14}$

It should be noted that the capacity estimates are only a reflection of the point at which an investment in PV would break even. Capacity estimates do not necessarily reflect whether a building owner would ultimately decide to undertake a PV project. The requirements of certain entities might be higher if they have minimum hurdle rates for investments, or it might be lower if they consider a PV system to have value beyond its bill reduction potential.

\footnotetext{
12 The analysis assumed a system financed with a $6.5 \%$ annual percentage rate, $80 \%$ debt fraction loan, a real discount rate of $6.5 \%$, and future electricity price projections from the EIA's Annual Energy Outlook.

13 The SunShot target for 2020 was originally $\$ 1.25 / \mathrm{W}_{\mathrm{DC}}$ in 2010 dollars, but it has been converted to 2016 dollars using the Bureau of Labor Statistics Consumer Price Index calculator.

14 These high fractions of potential capacity breaking even are based on the price and structure of electricity tariffs in 2016. In a future with extremely low-cost PV, it is likely that the amount of equally-low-priced utility-scale PV deployment would be significant enough to prompt changes in the structure or magnitude of retail tariffs.
} 
The breakeven point of PV is a useful metric for gauging the state of the market, but it includes embedded assumptions about financing and future electricity prices. An alternative metric is the average first year bill savings of the PV system, in terms of cents of bill savings per kilowatthour of electricity produced. This is useful for a rough characterization of the prices that could be set for power purchase agreements (PPAs).

Figure 8 shows a national demand curve for each building class in terms of the average first year bill savings. For example, a PPA that offered electricity at $10 \phi / \mathrm{kWh}$ would have its first-year cost equal the resulting first-year bill savings for $20 \mathrm{GW}$ of office capacity, $13 \mathrm{GW}$ of warehouse capacity, and $6 \mathrm{GW}$ of hotel capacity (see Figure 8). Whether the PPA would result in lifetime bill savings would be influenced by the PPA's escalation, electricity price changes, and any evolutions in electricity tariffs.

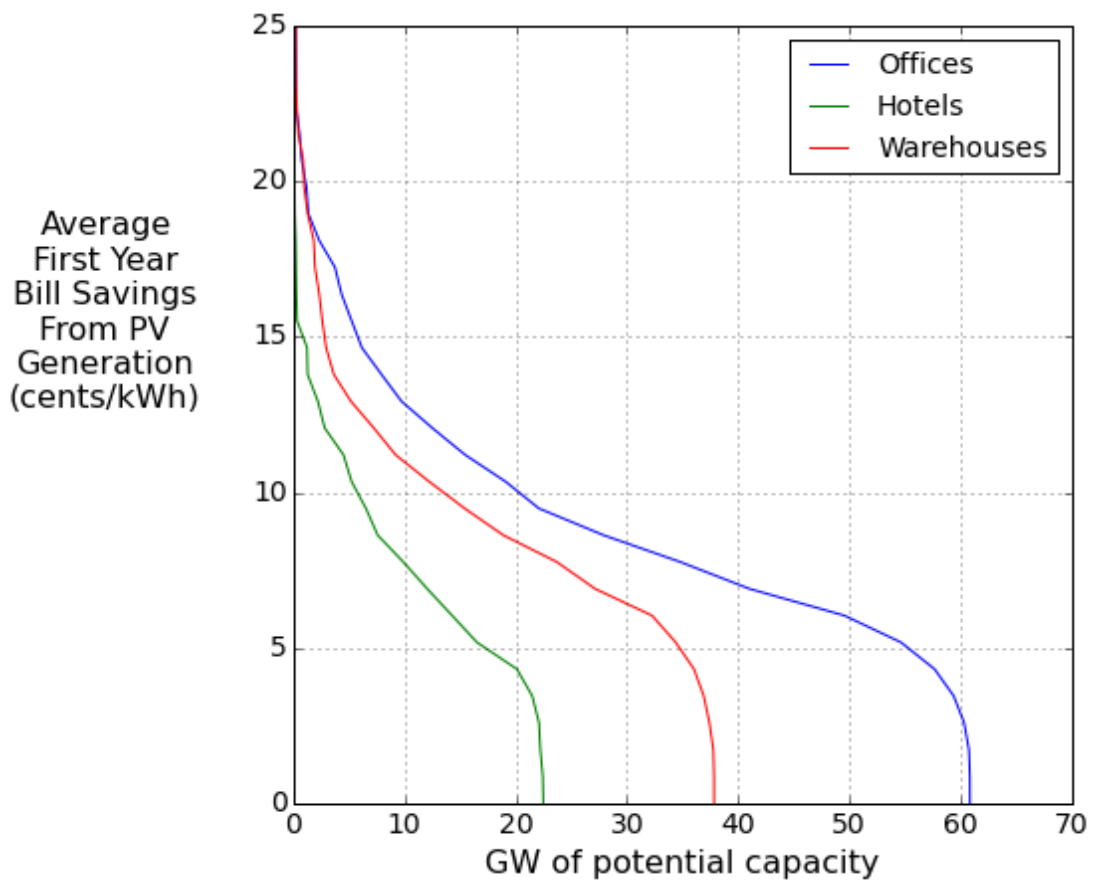

Figure 8. First year bill saving demand curves for offices, hotels, and warehouses

\subsection{National Technical and Economic Potential on Universities}

Universities have several characteristics that set them apart from most potential distributed PV customers. With respect to their technical potential, their large size typically offers significant potential for rooftop, parking canopy, and ground-mounted PV. Less intuitively, the electricity consumption of entire campuses are often aggregated and billed through one meter. This aggregation strengthens the financial value of PV because PV generation from any location on campus can influence the total load and decrease the demand charges more efficiently than if the generation was only influencing the load of a single building. Despite these advantages, many universities are on special electricity tariffs with low rates or large customer general service tariffs with large demand charges. Both of these factors decrease the solar value proposition. 


\subsubsection{National Demand Curve for Behind-the-Meter PV on Individual Universities}

Unlike the analysis performed for offices, hotels, and warehouses, our analysis of the university technical potential did not restrict the amount of PV by the availability of rooftop or land area. Rather, in constructing the demand curve for each individual university we evaluated a quantity of PV up to the amount that would generate $25 \%$ of the annual consumption of electricity from the campus. This is much larger than historically typical installations, which often only provide several percent of a university's annual electricity consumption — but is nonetheless shown here in order to explore a broad possible space.

The national demand curve for distributed PV on universities is shown in Figure 9. This shows that if every university in the nation deployed distributed PV up to a capacity that would generate $25 \%$ of their annual electricity consumption, the total capacity would be slightly greater than 16 GW.

The demand curve is characterized by two regions. The first region, on the far left, is a quantity amount of high-value capacity. This corresponds to the capacity that would, in addition to decreasing energy consumption charges, also be able to efficiently decrease the host university's demand charges. The detail box of Figure 9 shows that we estimated approximately $3.7 \mathrm{GW}$ of potential distributed PV capacity that would result in average bill savings greater than $10 \phi / \mathrm{kWh}$. This high value capacity is spread out in pieces of 100's of kWs across many universities in the U.S.'s stock.

The second region of Figure 9 is the broad, flat region extending from approximately $4 \mathrm{GW}$ to 16 $\mathrm{GW}$. This region corresponds to the capacity that would primarily be offsetting energy consumption charges, and is therefore of less value than the first region.

The methodology for generating the national university demand curve is discussed in Section 3.4.

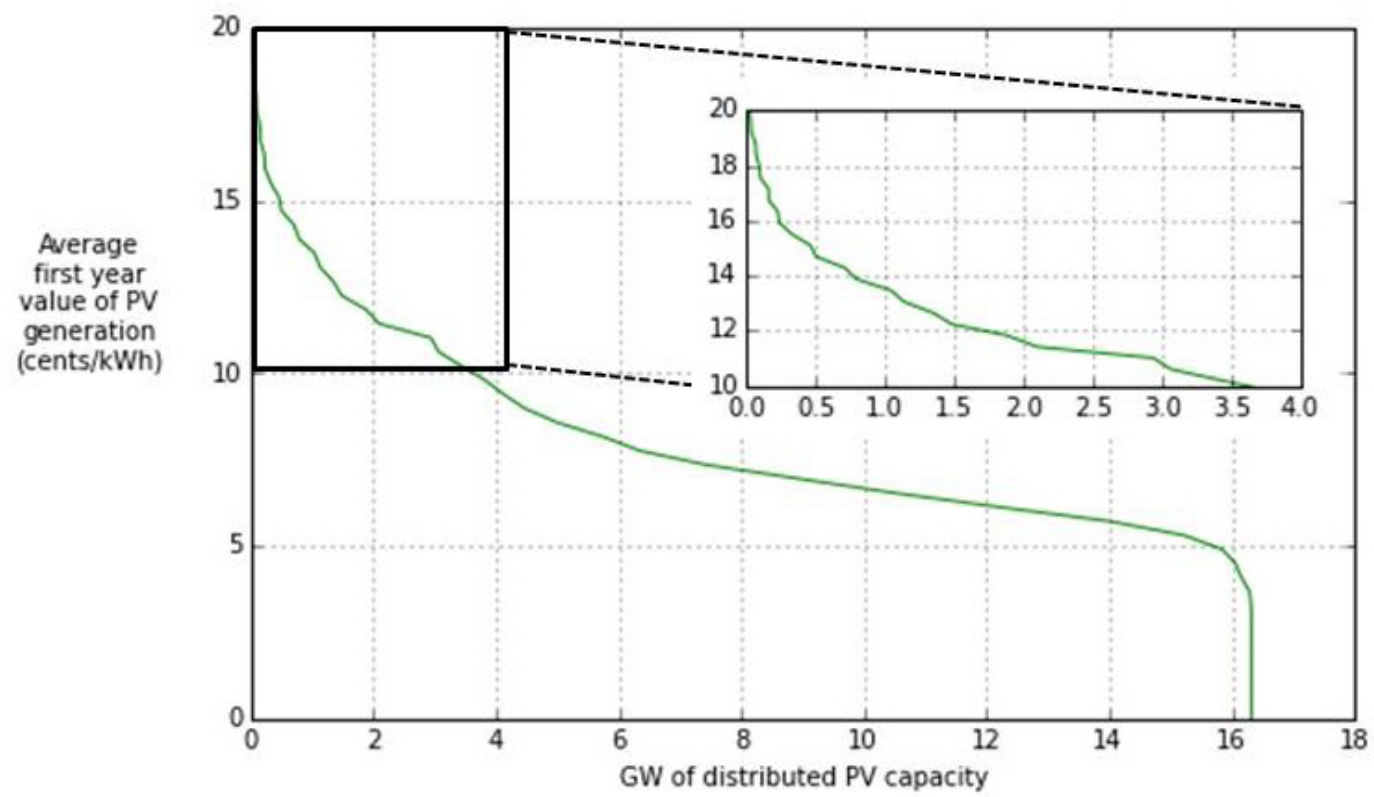

Figure 9. National demand curve for behind-the-meter PV on universities 


\subsection{Demand Curve Methodology for Offices, Hotels, and Warehouses}

This section gives a brief narrative description of the method and key assumptions used to create the demand curves for offices, hotels, and warehouses. The methodology used for universities differed; it is given in Section 3.4.

\subsubsection{Modeling Potential PV Customers}

To start the analysis of technical potential for commercial buildings, we needed to model the quantity and characteristics of the different potential PV customers within each of the building classes. First, we determined electricity consumption patterns of each of the buildings, which vary by season and region. For that, we turned to a previous effort at NREL that had simulated annual hourly load profiles for common commercial buildings for approximately 1,000 sites across the nation. ${ }^{15}$

Second, we examined roof area, which can be derived from floor space and the number of floors. Data on the national distributions of those characteristics for our segments are given in the U.S. Energy Information Administration's (EIA's) Commercial Building Energy Consumption Survey. For example, there are an estimated 230,000 offices with 5,001 to 10,000 square feet of floor space. Of buildings that size, $68 \%$ have one floor, $24 \%$ have two floors, $6 \%$ have three floors, and 1\% have four floors (EIA 2016a). Combining those two characteristics provides the building's roof area, but not how much of it is suitable for PV deployment. For that, we used data from another previous NREL effort that leveraged lidar data to characterize the suitability of rooftops across the nation. ${ }^{16} \mathrm{We}$ then combined these characteristics with the aforementioned electricity consumption profiles to create a set of more than 40,000 representative buildings with characteristics that represent national trends.

\subsubsection{Curating Electricity Tariffs}

That effort gave us a set of representative buildings, but in order to construct the demand curves, we still needed to determine the economics of PV for each of the buildings. Because commercial buildings tend to have complex tariff structures that significantly influence the value of PV, we used actual tariff structures - instead of simpler estimation methods like the average price of electricity. We curated a set of tariffs from the URDB. After cleaning the data set of errors and removing irrelevant entries, more than 3,000 commercial tariffs for over 300 utilities remained. In total, this set of tariffs covers $49 \%$ of the megawatt-hours of electricity sold to the commercial sector (EIA 2016b). We assumed this tariff set was representative of the behind-the-meter value of PV across the nation, and therefore extended the relevant economic metrics to regions not covered by the tariff set.

\subsubsection{Modeling PV Performance}

Using NREL's System Advisor Model (SAM) (Blair et al. 2014) and typical meteorological weather data (Wilcox and Marion 2008), we then determined the productivity of PV on each of

\footnotetext{
${ }^{15}$ See http://en.openei.org/doe-opendata/dataset/commercial-and-residential-hourly-load-profiles-for-all-tmy3locations-in-the-united-states.

${ }^{16}$ The suitability of roof area for hosting a PV system was determined by four criteria, as discussed in Gagnon et al. (2016). The roof area could not be facing north, not be excessively shaded, not tilted more than sixty degrees, and consist of at least $10 \mathrm{~m}^{2}$ of contiguous area.
} 
the representative buildings. We then evaluated the price of electricity with and without the PV system for each building, and determined the bill savings from PV as the difference between the least cost tariffs in both scenarios. ${ }^{17}$

\subsubsection{Evaluating Economic Performance}

We then evaluated the relevant financial metrics, which vary as appropriate throughout this report. The most common is the breakeven point - the total installed price at which PV will exactly pay itself off over the assumed lifetime of the system. To evaluate the breakeven point, we projected the annual bill savings over the lifetime of the system and used standard discounted cash flow modeling to determine what initial price would have resulted in a net present value of exactly zero. Bill savings were calculated as the difference between the lowest cost of electricity without PV against the lowest cost of electricity with PV for all tariffs available to a given customer - meaning that we represented the potential to switch tariffs in the analysis.

Furthermore, because the bill savings of PV varies depending on how much PV there is on the building already, we modeled the financial performance of many different PV sizes. Therefore, our following analysis can capture instances where a $50 \mathrm{~kW}$ PV system on a large office may have a positive net present value, even when a $250 \mathrm{~kW}$ system on the same office would not have broken even.

\subsubsection{Aggregating the Results into Demand Curves}

The individual results for each of our 40,000 representative buildings were then aggregated into national demand curves, where the contribution of each simulated building was weighted by the number of actual buildings it represented.

\subsection{Demand Curve Methodology for Universities}

Because of differences in data availability, the process for constructing a national demand curve for universities differed from the method for offices, hotels, and warehouses, which was described in Section 3.3. Unlike the other building classes, we did not have the data to construct a large set of representative universities. Instead, we used data from seven actual universities to characterize the value of PV for those universities as a function of the quantity of PV installed on campus. By normalizing the results against the state's average price of electricity and the university's enrollment, we identified a general trend that, in combination with each state's electricity rates and enrollment numbers, enabled an estimate of the nation's total demand curve.

\subsubsection{Constructing Individual Demand Curves for a Set of Universities}

We obtained the energy consumption profiles for seven individual universities. ${ }^{18}$ Using SAM, we evaluate the average reduction in annual electricity bill per $\mathrm{kWh}$ of PV-generated electricity. Two of the universities were on special tariffs for educational institutions - which had less expensive rates - and the rest were on the local utility's version of a General Service tariff for large customers.

\footnotetext{
${ }^{17}$ When selecting what tariffs a building could subscribe to, we respected eligibility criteria such as minimum and maximum peak demand or energy consumption.

${ }^{18}$ Because of the sensitivity of the data, the universities will remain anonymous.
} 
The resulting curves are shown in Section 4.3.2, and accompanied by a discussion of how the value of PV tends to decline for universities as the capacity of installed PV grows.

\subsubsection{Calculating a Normalized Demand Curve for Universities}

Each of the individual demand curves for the universities showed similar shapes, indicating the opportunity to normalize them and create a general trend that could be applied to a larger set. First, the cents-per-kilowatt-hour value of PV was normalized by the average price of electricity for the industrial sector in each university's state (EIA 2016b). The amount of capacity available at each normalized value was then summed together across all seven universities. Lastly, the capacity value of the aggregated curve was then normalized by the total full-time equivalent students between all seven universities. The result was a generalized demand curve that reflected the normalized value of PV as a function of the number of full-time equivalent students in a portfolio of schools.

\subsubsection{Calculating a National Demand Curve for Universities}

Having developed a normalized demand curve for universities, we could generate a demand curve for each state in the nation by multiplying the capacity of the curve against the number of full-time equivalent students in the state, and the PV-value by the average price of electricity in each state. ${ }^{19}$ We then aggregated the state curves into a single national curve (Section 3.2).

\subsection{Key Limitations and Assumptions}

The key assumptions used in the construction of the demand curves are listed in Table 1 and Table 2.

Table 1. Technical Assumptions used in Demand Curve Generation

\begin{tabular}{ll}
\hline Characteristic & Value \\
\hline System Size & Constrained by suitable roof area \\
Module Type & Multicrystalline silicon \\
Module Power Density & $160 \mathrm{~W} / \mathrm{m}^{2}$ \\
Tilt & 15 degrees \\
Azimuth & 180 degrees (south facing) \\
Ground Coverage Ratio & 0.70 \\
Total System Losses & $14.08 \%$ \\
Module Degradation & $0.75 \% /$ year \\
Inverter Efficiency & $95 \%$ \\
DC to AC Ratio & 1.4 \\
\hline
\end{tabular}

\footnotetext{
${ }^{19}$ State-level enrollment data was obtained from Table 304.10 of the Digest of Education Statistics, and the average price of electricity in the industrial sector was obtained from EIA Form 861 (EIA 2016b).
} 
Table 2. Financial Assumptions used in Demand Curve Generation

\begin{tabular}{ll}
\hline Assumption & Value \\
\hline Project lifetime & 25 years \\
Loan Term & 20 years \\
Loan Rate & $6.5 \%$ (real) \\
Debt Fraction & $80 \%$ \\
Federal Tax Rate & $35 \%$ \\
State Tax Rate & $7 \%$ \\
Inflation & $2.5 \%$ \\
Discount rate & $6.5 \%$ (real) \\
ITC & $30 \%$ \\
Depreciation & Modified Accelerated Cost \\
& Recovery System with bonus \\
& depreciation \\
\hline
\end{tabular}

The power density used corresponds to a module with approximately $16 \%$ efficiency, which is the median efficiency of polycrystalline modules installed during 2015 (Barbose and Darghouth 2016). The losses from soiling, shading, snow, wiring, and other sources are captured in the total system losses parameter, which was chosen to remain at the SAM default value for this analysis. This level has been selected to be representative of typical systems. The real discount rate was set to equal the loan rate, although the actual value used would likely vary significantly across potential customers.

As with any analysis, the construction of the demand curves involved some simplifying assumptions:

- We did not consider rooftop age or structural ability of the buildings to host a PV system. Our definition of a suitable rooftop only excluded area due to shading, orientation, minimum contiguous area, and tilt. While rooftop age is a significant barrier for any given year, rooftops will eventually be replaced, reducing the impact of this assumption over time.

- We did not represent barriers from building occupiers not owning the building.

- We used electricity prices and tariff structures current as of June 2016.

- We did not represent any complimentary technologies or energy management strategies, such as a hot water heater with demand response or off-peak pre-cooling of a building. Beyond their intrinsic value, these load management behaviors would increase the bill savings of PV in most situations. 


\section{Opportunities and Barriers to Midscale PV Market Deployment}

While there is significant techno-economic potential for deployment of PV in the midscale market, other considerations can influence the decision to install PV. This section explores both the opportunities that PV presents to midscale market customers (e.g., demand charge savings, achieving sustainability goals) and the barriers to installation (e.g., split incentives, transaction cost), based on interviews with market participants, relevant literature, experience with providing technical assistance to universities, and our analysis of PV system economics in the four building segments. For this report, we interviewed about a dozen industry stakeholders, representing a cross-section of PV developers and installers, end-users, and individuals involved in legal negotiations and contracts.

First, we explore the benefits and barriers that are common across the midscale market space and then focus more narrowly on specific opportunities and challenges for the four building types considered in this analysis: offices, hotels, warehouses, and universities.

\subsection{Opportunities in the Midscale Market}

There are a variety of financial and non-monetary benefits that PV systems can provide to commercial-scale customers, which can substantially influence the decision about whether to install PV. The following benefits are common across participants in the midsize market segment; however, the degree to which each of these influences the purchasing decision varies by building type, energy use patterns, the type of business or organization, and how the business interfaces with customers. In subsequent sections, we will examine drivers for specific building categories.

Energy Savings/Bill Stabilization: PV systems can result in energy savings and may provide greater certainty about future energy bills, which can be attractive for property owners or tenants. Energy savings offset upfront installation costs for host-owned systems, or result in net energy bill savings, as is typically the case of third-party solar PPAs. In either case, PV can provide a hedge against future energy costs because the primary costs of the PV system are associated with the upfront capital costs. However, one challenge for midscale market systems is that the bill savings are lower on a per-kilowatt-hour basis than for residential customers, because of differences in utility rates. A detailed discussion of energy savings and how this differs by building type is discussed in Section 4.3.

Demand Charge Savings: PV customers may also be able to reduce demand charges. ${ }^{20}$ Demand charges are based on the kilowatts of power a building extracts from the grid-most often the peak demand over the course of a month. The degree to which building electricity loads align

\footnotetext{
${ }^{20}$ Commercial electric bills are commonly composed of three components: a fixed charge, an energy charge for each kilowatt-hour consumed, and a demand charge based on the maximum kilowatts of power a building extracted from the grid over the course of a month. Fixed charges typically cannot be influenced by a PV system because they are constant regardless of a building's consumption. Both the energy consumption charges and the demand charges can be reduced by PV.
} 
with PV system output substantially impacts the magnitude of potential demand charge savings. The size of the PV system that can be installed relative to loads, as well as the specific utility demand charge design, affects the potential for savings. A more detailed discussion of the variation of demand charge savings by building type is discussed in Section 4.3.

Achievement of Sustainability Goals: Installing onsite PV can be one method of achieving sustainability goals, if the RECs from the system are retained. For example, many corporations, universities, governments, and NGOs have established targets for reducing greenhouse gas emissions or using renewable energy to meet their energy needs. Installing onsite PV is one method of meeting these goals. However, no environmental claim can be made if RECs are not retained, as is common in markets with high solar REC prices (e.g., New Jersey, Massachusetts, and Washington, D.C.).

Green Building Certification: The installation of onsite PV can help organizations achieve points that count toward achieving green building certification. For example, the U.S. Green Building Council's Leadership in Energy \& Environmental Design (LEED) certification program provides credit for the use of solar energy as one component of achieving certification as a green building.

Higher Rents/Customer Value: The energy savings from PV result in reduced operating costs, which could potentially be transferred to occupants in the form of higher rents. The use of PV may also make the building more attractive, enabling the property owner to command higher rents. Studies of green buildings have shown that sustainability features are desired by tenants and some are willing to pay more for these features (Devine and Kok 2015).

\subsection{Barriers to Deployment in the Midscale Market}

Commercial buildings have a number of barriers that are common across various building types and uses. Market participants active in solar installation in the commercial building space identified the following as among the most challenging barriers to the midscale solar market.

Tenant/Landlord Split Incentive: One of the most significant barriers to the installation of PV on commercial buildings is the tenant/landlord relationship. Often, commercial buildings are separately metered for electricity and the tenant pays the energy bill, but the owner is responsible for maintenance and upgrades to the building structure. Therefore, a split incentive is created if bill savings from the PV system go to the tenant, but the building owner faces the installation challenges without reaping the benefits. This can lead to instances in which the building tenant is interested in purchasing solar, but the building owner does not have interest or an economic stake in the project. Individual tenants may also not have sufficient loads to justify a project. In cases where the landlord provides all of electricity to the tenants, then PV can be attractive and the landlord can have a vested financial interest in the project. For reference, in the United States $57 \%$ of office buildings, $45 \%$ of warehouses and storage units, and $21 \%$ of lodging buildings are not owner-occupied (EIA 2016a). ${ }^{21}$

Building Ownership or Lease Term: The expected length of ownership of a commercial building is an important consideration for PV installations. Building types with frequent ownership

\footnotetext{
${ }^{21}$ Owner occupancy numbers are for non-governmental buildings.
} 
changes can be challenging because the lifetime of the PV asset is at least 20-25 years.

Typically, buildings are likely to remain under the same ownership for at least 10 years; 20-year owners may be the best candidates for solar. Similarly, if a building is leased, often the term of the lease is significantly shorter (e.g., 6-8 years) than the 20 plus year lifetime of the PV asset. This discrepancy in duration of the PV asset and building contract length makes it difficult to finance projects. Typically, financing PV to yield positive economic benefits requires spreading costs over a 15-20 year period. For third-party owned financing structures, where revenues are collected over time from the end-user, the shorter lease length creates power sales risk. If the power purchaser leaves the building after the lease term, the third-party PV system owner has to sell the power into the wholesale market, to the building owner, or to another entity. This uncertainty creates additional risk and makes such contracts less attractive. Often solar providers want the building owner to guarantee the PPA contract and revenues in case of vacancy (Navigant Consulting 2015a).

Building Ownership Structure: The type of entity that owns a building can have implications for the viability of PV projects as well. Some commercial buildings are owned by LLCs, which often do not have sufficient tax liability to utilize the federal investment tax credit (ITC). Likewise, universities, as public or nonprofit entities, cannot claim the federal ITC directly. Properties that are owned by joint ventures, where multiple parties must approve contracts, can also make PV projects challenging. This can be true for hotels, in particular. Many commercial buildings are owned by real estate investment trusts (REITs), which may only own the building asset for a short time.

Roof Conditions and Obstructions: For midmarket rooftop systems, key considerations for evaluating the potential for installing a PV system are the condition of the roof and whether there are any obstructions to the installation. The condition of the roof is a key element of rooftop system economics. Buildings with roofs that have 15-20 years of life left are ideal for PV installations. Roofs that are already 10-15 years old and not ready for replacement can be problematic because the PV system would need to be taken down when roof replacement is required - adding substantial cost that is typically paid by the off-taker. In addition, if the roof needs an upgrade to hold the racking, this adds extra costs to the installation. Planned roof replacement yields the best economics because some of the roof replacement can be paid for as part of the PV installation.

Another consideration is that the impact of PV on the life of an existing roof is unknown. PV installations can cause stress to the roof through wind, snow, and weight loads as well as penetrations, but can reduce foot traffic and provide protection to covered roof sections. Roof issues (except for obstructions) may not be as challenging for ballasted PV systems that do not penetrate the roof. Generally, it is ideal if any obstructions to the PV installation, such as HVAC equipment located on the roof, are on the north side of the building to reduce the shading from the obstructions.

Creditworthiness of Off-Taker: For third-party owned systems or host-owned systems financed with a loan, the creditworthiness of the off-taker is an important consideration for enabling project financing. Under the PPA business model, the third-party owner puts up the capital to install the system, but requires a creditworthy off-taker to finance the project. For commercial and industrial projects, it can be difficult for developers to get credit profiles of potential off- 
takers. Lack of credit rating systems can be an issue for some commercial entities (e.g., REITs and real estate companies that establish a separate LLC for each building); there is a commercial FICO score for public but not private companies.

Transaction Costs: A key factor affecting growth of midscale solar market is the relatively high fraction of transaction costs given the project size. Transaction costs, which may be similar in dollars to those of larger systems, can represent $5 \%-20 \%$ of the deal for midscale projects. Transaction costs cannot be spread over a larger base as for larger system and are much more complex than a residential project. Building owners typically have legal teams and specific requirements, but generally have limited experience with solar market transactions, which can lead to an extended negotiation process, sometimes involving relatively small building-specific details. In general, standardized contracts are not widely used, although the size and economics of midscale market projects typically cannot support extensive negotiation.

Interconnection Issues: The interconnection process for midsized, behind-the-meter systems can be similar to that for larger utility-scale systems, even though much of the electricity is consumed on site rather than exported entirely to the grid. Thus, for midsized systems, the interconnection process often imposes a disproportionally large cost burden, which unfavorably affects project economics. Key challenges include a lack of interconnection cost certainty, potentially onerous impact studies, and relatively long processing and approval times. A recent analysis of interconnection timelines found that for a limited sample of midscale projects (250 $\mathrm{kW}-2 \mathrm{MW}$ ) the median time for utilities to review and approve an interconnection request is 51 days (Ardani et al. 2015). Additional time is needed to complete the final permission to operate (PTO) process, which may require additional utility inspections or witness testing. While time frames for the final PTO process vary widely across utility territories, the median for projects sampled was 18 days. Ultimately, project delays due to interconnection are more common for the midscale market than for smaller distributed PV projects (250 kW and under), with detailed impact study commonly required for any project greater than $1 \mathrm{MW}$ (Ardani et al. 2015). PV installers often downsize projects to avoid the detailed study process, because its long duration and high costs can place financing at risk or render a project economically unfeasible.

Permitting Process: Permitting processes can be very involved in some jurisdictions, particularly in downtown areas and larger cities. In general, large rooftop projects are more difficult to get permitted than ground-mounted projects because of zoning and contractual issues. In some cases, there is no clear right of appeal for permitting decisions. If jurisdictions have statutes that make it clear that solar has the right of way, this facilitates permitting. Some states have forbidden local land-use restrictions, and in these instances, the local authority cannot deny a permit for a solar system because it is considered unsightly.

\subsection{Building-Specific Considerations}

Each of the four market segments - hotels, offices, warehouses, and universities - has its own set of considerations that influence the decision of whether to install PV. While there are benefits or challenges that are common across the midmarket generally, as discussed above, the magnitude of impact that these factors has on the PV installation decision by a particular building segment varies. The following sections of this chapter provide a more detailed discussion of the specific factors that influence the decision to adopt PV for each of the four building categories. First, we 
examine electric bill reduction benefits and how they vary by building type, and we then focus on other considerations for each building segment.

\subsubsection{Electric Bill Reduction from PV on Commercial Buildings}

A building's energy consumption charge and demand charge can both be reduced by PV, as explained below. In general, a challenge for the midmarket is that the per-kilowatt-hour energy savings from PV are significantly lower for commercial customers than for residential customers. For example, commercial customers may pay utility rates of $4-6 \notin / \mathrm{kWh}$ or less for energy compared to the perhaps $10-12 \phi / \mathrm{kWh}$ paid by residential customers. Therefore, demand charge savings are important for overall project economics, but these can vary based on the commercial customers load profile relative to PV output.

\section{Reduced Energy Consumption Charges on Commercial Buildings}

The magnitude of energy savings can also depend upon how much energy is used onsite versus being exported to the grid and local policies addressing exports. For PV systems whose generation is small relative to their host building's energy consumption, the energy savings are relatively straightforward. For every kilowatt-hour generated by the PV system, one less kilowatt-hour is purchased. Potential energy savings are often constrained by the amount of roof area suitable for hosting PV systems - an amount that typically cannot fully meet building loads.

When systems are relatively large, savings are influenced by the amount of electricity exported from the host building to the utility grid. The monetary value of the exported electricity depends on the utility's net metering regulations, which vary considerably by state. Often states or utilities have caps on the size of commercial PV systems that are eligible for net metering - these can range considerably by state from roughly $100 \mathrm{~kW}$ to substantially more than $2 \mathrm{MW}$.

Generally, net metering allows the exported electricity to earn a credit equal to the retail rate, but some jurisdictions have made changes to net metering policies in recent years, modifying the terms (North Carolina Clean Energy Technology Center 2016).

Figure 10 through Figure 12 have a set of vertical lines corresponding to the maximum sized PV system that a building of the given floor space could host on its roof, depending on how many stories it had. For example, a 54,000 square-foot office with five equally sized stories could host a $65-\mathrm{kW}$ PV system. This calculation includes a derate for the fraction of roof on large buildings that is typically suitable for PV deployment, as informed by a previous NREL effort analyzing lidar data (Gagnon et al. 2016).

Figure 10 through Figure 12 also show the relationship between a PV system's size and the annual fraction of its generation that is exported. Each line terminates at the point where the PV system's annual generation would be equal to the host building's annual consumption. For example, the small 5,500 square-foot office we modeled in Daggett, California, could generate an amount equal to its annual consumption with a 40-kW PV system, and such a system would export $45 \%$ of its annual generation. Daggett, Kansas City, and Seattle were selected to represent a range of high, medium, and low quality solar resources. 


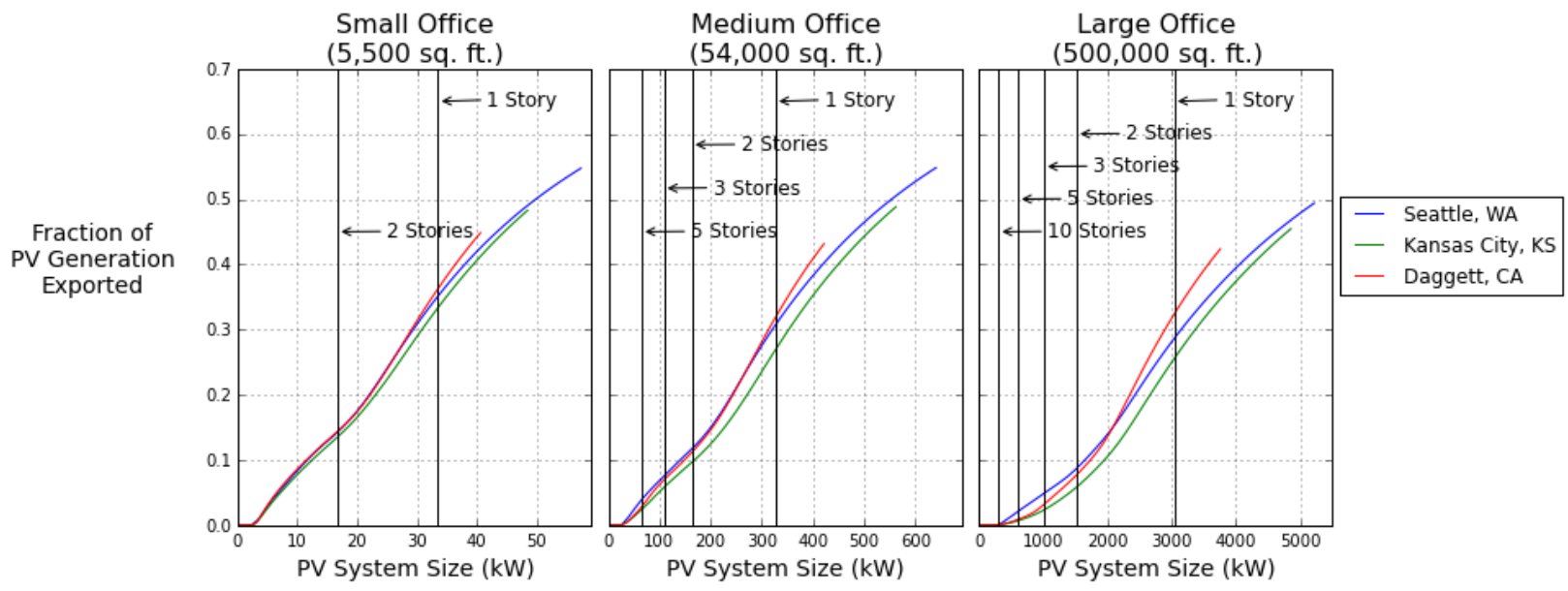

Figure 10. Exported PV by office size

The three office sizes start exporting electricity with fairly small systems - ones that achieve slightly less than 5\% annual energy penetration (Figure 10). This exportation at low system sizes largely stems from low electricity consumption on the weekends. Additionally, Figure 10 shows that PV systems sized to equal the host's annual energy consumption would end up exporting approximately $50 \%$ of the electricity the system would generate. This is unlikely to be realized for medium and large offices, however, because they typically do not have the roof area to host such large systems. For example, a typical 500,000 square-foot office with ten stories could host a 300-kW PV system, which would export effectively none of the PV generation. This illustrates a broader trend: multistoried office buildings do not have enough roof space to host systems large enough to export a significant fraction of their generation. Therefore, those systems are insensitive to how exported energy is compensated.

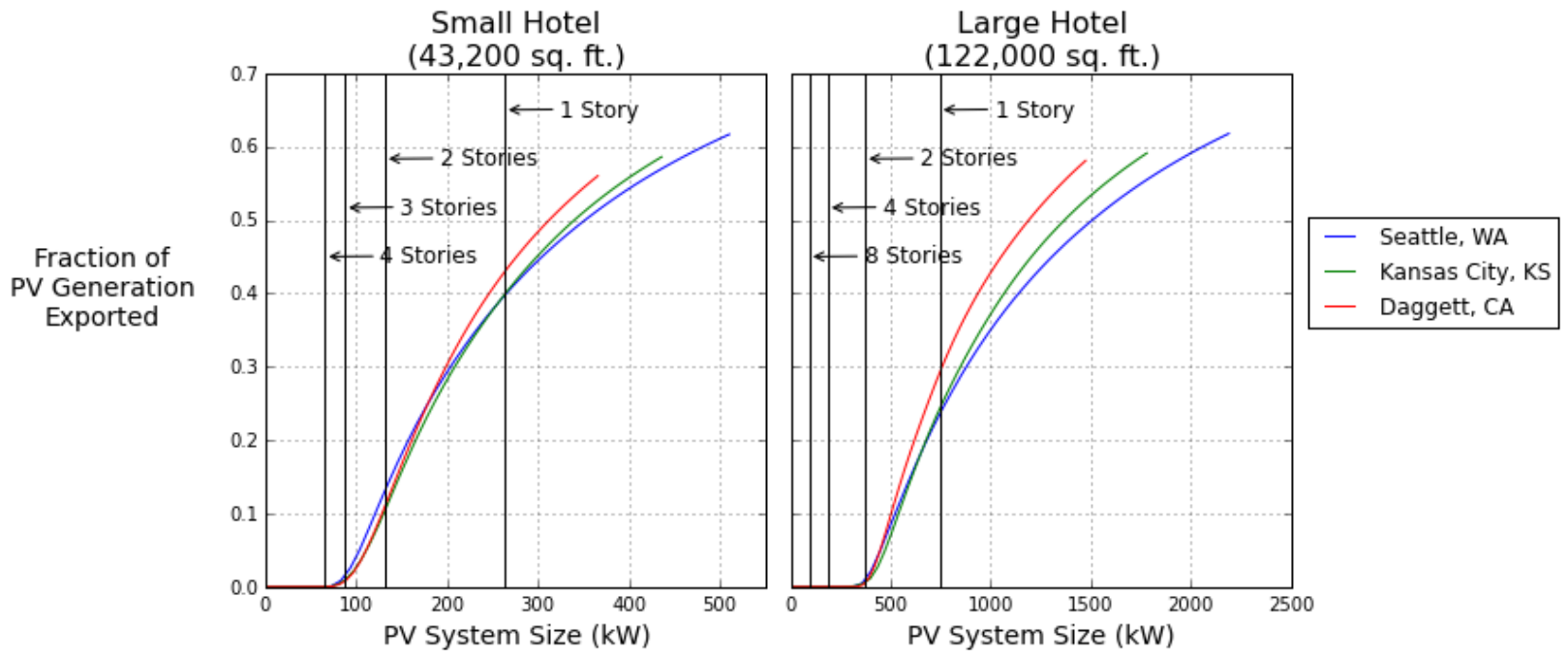

Figure 11. Exported PV by hotel size

In contrast to offices, our simulated hotels can host PV systems that supply a larger fraction of their annual energy consumption before exporting any PV generation-ranging from $12 \%$ to 
$20 \%$ depending on the building size, location, and use patterns (Figure 11). The higher fraction, as compared to offices, is largely due to the occupancy of the hotels on the weekends. Levels of exportation rose rapidly beyond that point due to less consumption during the daylight hours. Ultimately, between $56 \%$ and $62 \%$ of generation was exported from hotels that had systems sized to generate equal to their annual consumption. As with offices, multistoried hotels would likely not have the suitable roof area necessary to build a system large enough to export a significant fraction of its generation. For example, our 43,000 square-foot hotel with three stories would export approximately $2 \%$ of its annual generation if it filled its roof with $\mathrm{PV}$, and our 122,000 square-foot hotel with four or more stories would export effectively none of its PV generation.

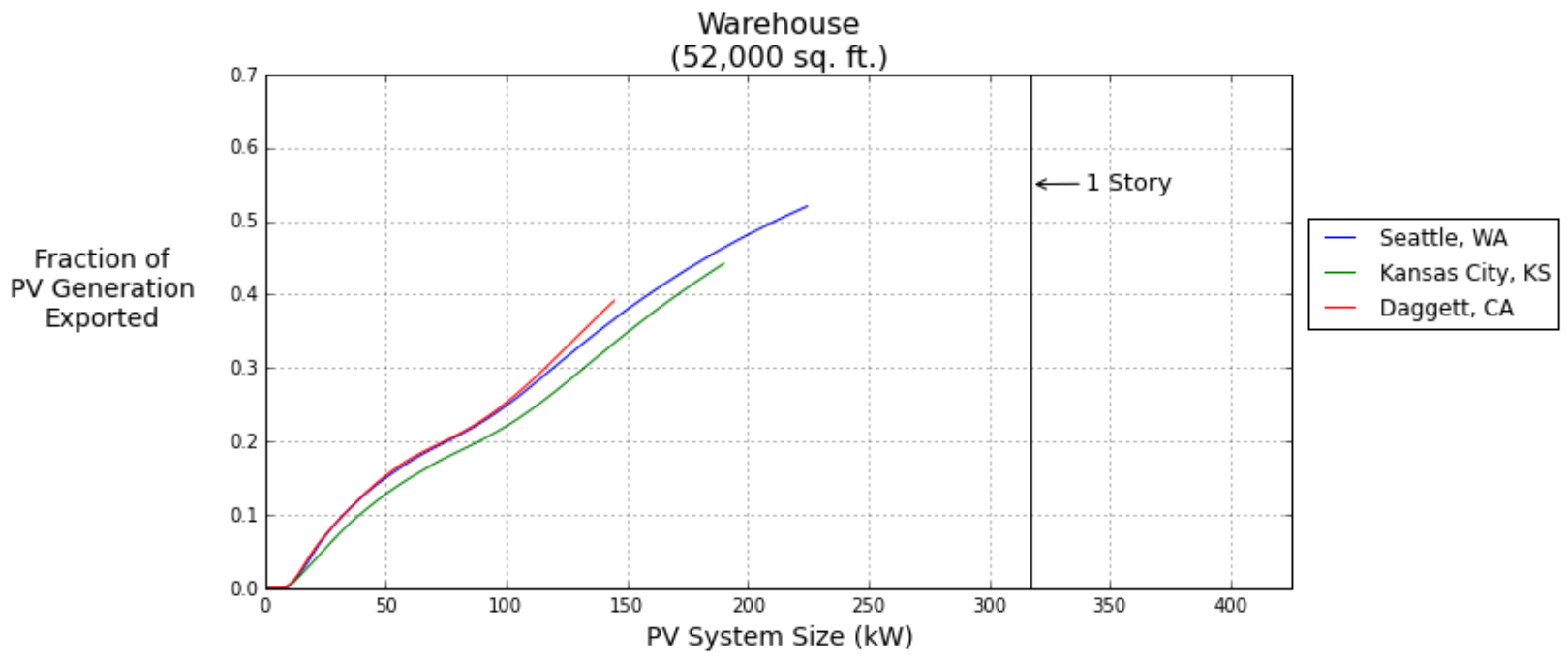

Figure 12. Exported PV for warehouses

The most noteworthy feature of typical unrefrigerated warehouses is the fact that their abundant roof area, tendency to be single-storied, and relatively low electricity consumption per square foot of floor area lead to them having the potential to install systems much larger than what would generate an amount equal to their annual electricity consumption (Figure 12).

\section{Reduced Demand Charges on Commercial Buildings}

The reduction of a building's monthly peak demand from a PV system is often only a small fraction of the system's maximum power output. Also, the level of demand charge savings is not guaranteed and can vary with changes in PV output and how well it correlates with building demand. Variability in solar irradiance from changes in weather can create spikes in the total net load. A temporary period of cloudiness, when PV is not available, can set the level of a building's peak demand in an otherwise sunny month - thereby significantly reducing the PV system's influence on demand charges. This effect can be mitigated with solar load controllers, although the analysis in this report did not consider supporting technology of that type.

In addition, the efficiency of a PV system in reducing a building's peak demand depends on the alignment between the building's peak load and PV system output. In general, the ability of PV to generate demand charge savings decreases with larger PV system sizes. This is because 
increasing quantities of PV generation shift the hour in which the building's net load peaks either later or earlier in the day, when the PV system's output is decreased and is less effective at reducing the load.

This trend is shown with a examples of an office, hotel, and warehouse in Figure 13 through Figure 15. Each figure shows the original load profile of the day on which the building's demand peaked in the month of October. Additional lines are given that show what the net load would have looked like if PV systems of varying sizes had been installed on the building. ${ }^{22}$ The values indicate the percentage of the building's annual energy consumption that would be provided by $\mathrm{PV}$. The right panel in the figures shows what the month's peak demand was for a range of PV system sizes. This is just the reduction in peak demand for a particular example month - as mentioned above, variation in solar irradiance could reduce the effectiveness of PV at decreasing peak demand in other months.
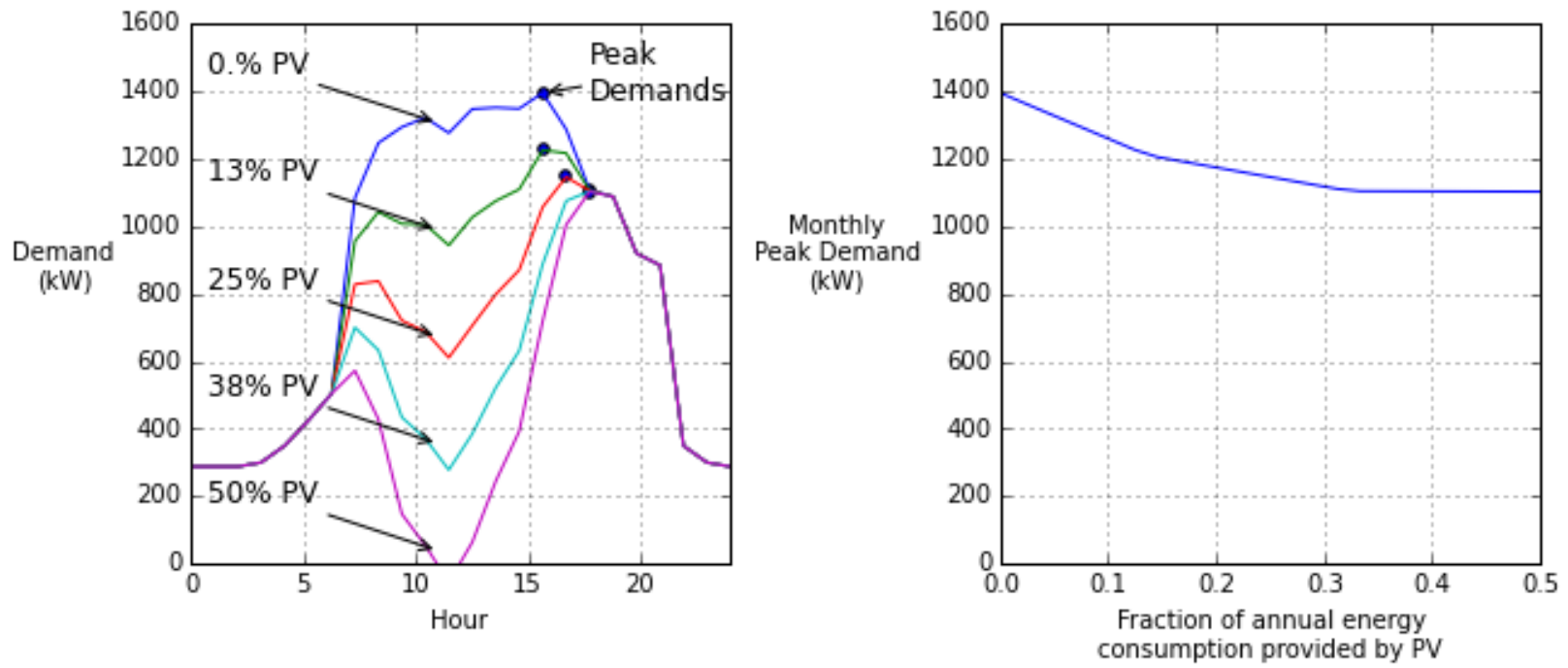

Figure 13. Example of influence of increasing quantities of PV on October's monthly max demand for a large office building in Denver

As greater quantities of PV are installed, the peak demand shifts to later in the day for the example large office building (Figure 13). The first $567 \mathrm{~kW}$ (which would generate 15\% of the building's annual consumption) was moderately effective at shifting the peak - the building's peak demand occurred at 4 p.m., four hours from peak PV production. For every kilowatt of those first $567 \mathrm{~kW}$, there was a $0.35 \mathrm{~kW}$ reduction in the month's maximum demand-illustrated by the curve on the right side of the figure. Once a system larger than $567 \mathrm{~kW}$ was installed, however, the hour of peak demand shifted to a later hour. Beyond this point, the reduction in peak demand per kilowatt of additional PV was lower. With a system size of $1,300 \mathrm{~kW}$, the peak demand of this particular office moved outside of daylight hours, and no amount of additional PV could further reduce demand charges.

${ }^{22}$ SAM was used to determine the net loads. 

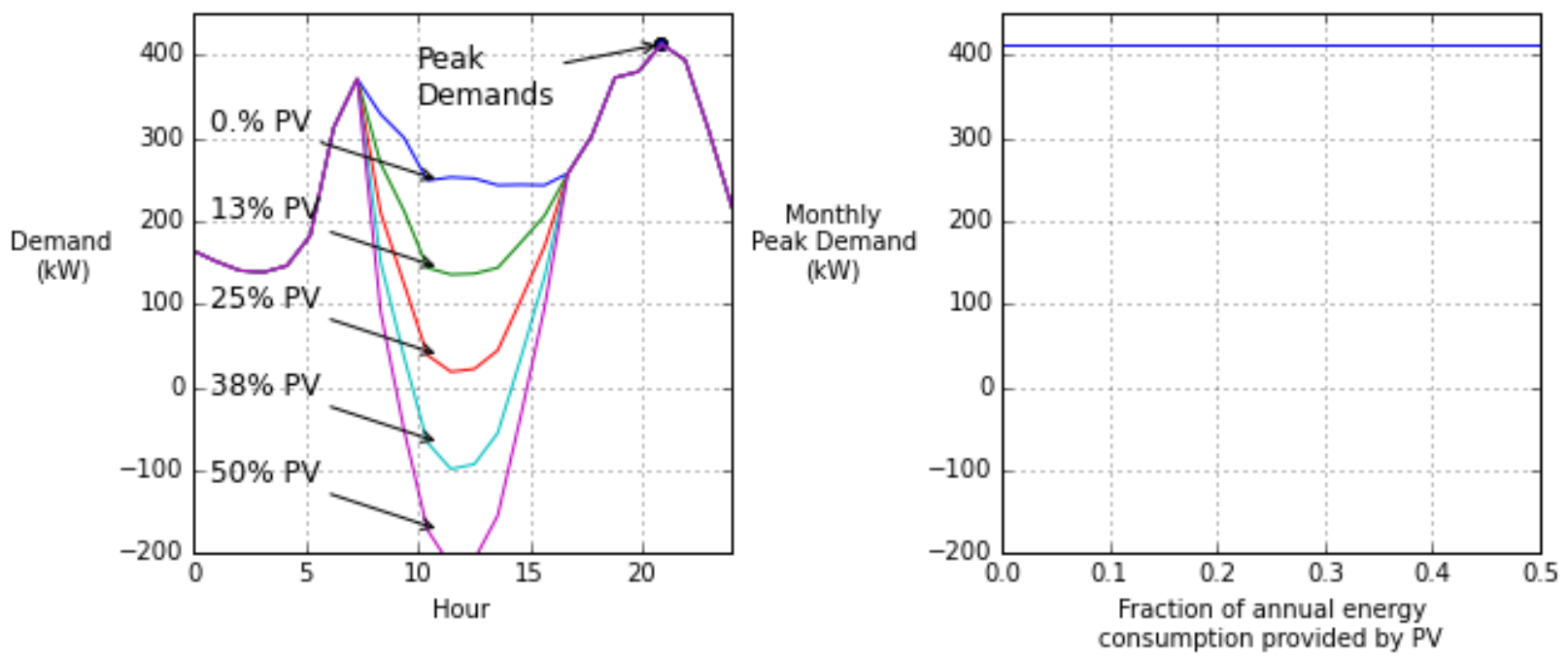

Figure 14. Example of influence of increasing quantities of PV on October's monthly max demand for a large hotel in Denver

In contrast to the profile of the office building, Figure 15 shows a hotel with an inverted profile that has its peak demand occur during the evening. In a situation such as this, PV cannot reduce the building's peak demand, and therefore cannot reduce the building's demand charges. ${ }^{23}$ Intelligent load management strategies, such as precooling buildings or co-locating hotels with other facilities, can result in a non-inverted load profile. Therefore, this example should be the general trend of a building with an inverted profile, and not a statement about all hotels.

\footnotetext{
${ }^{23}$ This is assuming the building is on a traditional demand charge structure that sets demand as the month's peak at any hour. Buildings on more advanced tariffs that have time-of-use or coincident peak components could still reduce their demand charges with PV, even if their peak demand was outside of daylight hours. These types of tariffs are uncommon, but may become more common as utilities seek to send more accurate price signals to potential distributed PV customers.
} 

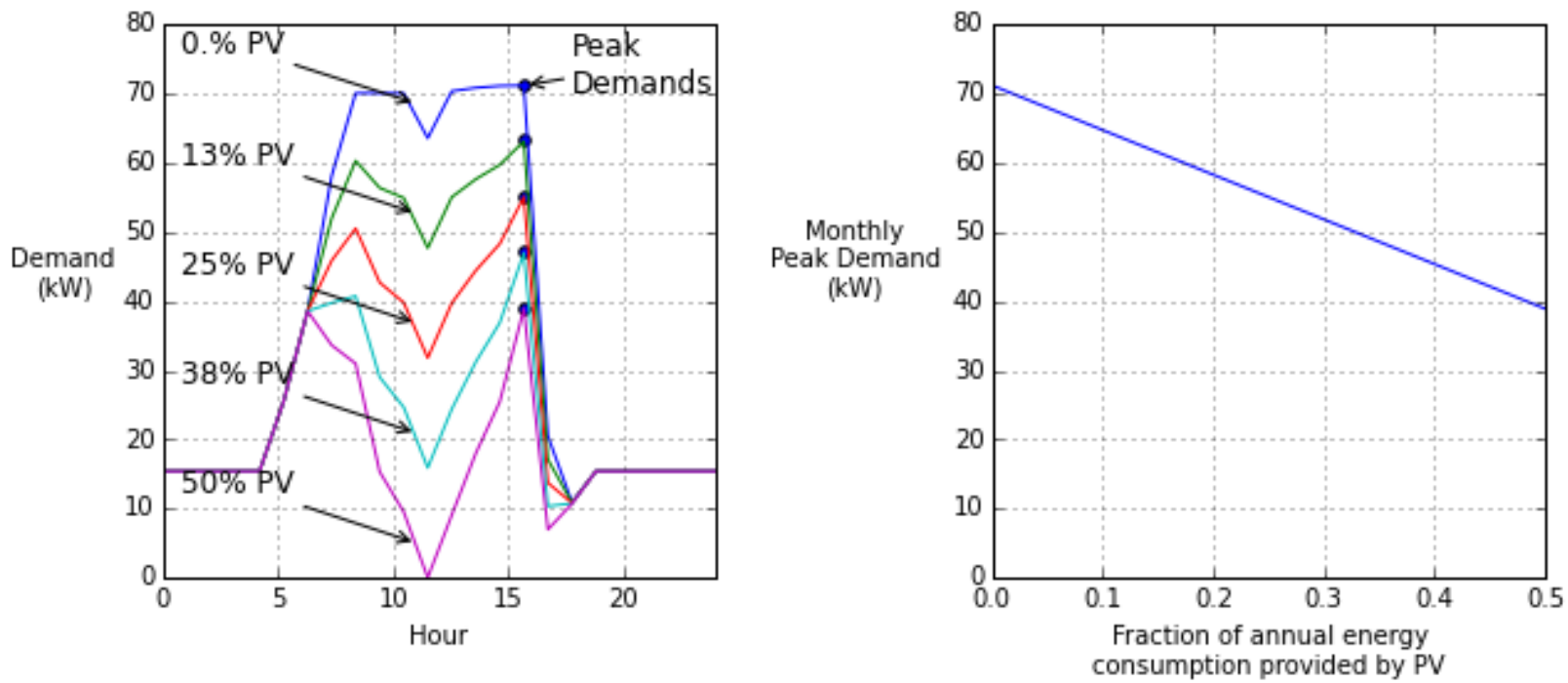

Figure 15. Example of influence of PV on October's monthly max demand of a warehouse in Denver

The warehouse in our set of examples had a peak load that occurred at 4 p.m. and had a sharp drop in electricity consumption after that point. The result was a constant reduction in peak demand of $0.35 \mathrm{~kW}$ per kilowatt of PV installed. If the building's consumption had remained at that level for another hour, we can see that the resulting decrease in peak demand per kilowatt of PV would have been significant reduced. This emphasizes the sensitivity of demand charge savings from PV to the degree to which electricity consumption is maintained into the evening.

The above illustrations are based on example buildings. Many buildings within each class will have load profile shapes that deviate significantly from these figures. Further, electricity savings may be achieved as PV system sizes increase, even if the demand charge component is no longer affected. And for multistoried buildings, roof area constraints would often prevent the installation of large enough PV systems to drastically shift the hour of peak demand.

\subsubsection{Electric Bill Reduction from PV at Universities}

To explore energy and demand charge savings at universities, we calculated the bill savings of seven universities for varying amounts of PV in the Midwest, West, and South census regions. ${ }^{24}$ The universities vary in size from fewer than 2,000 full-time students to more than 20,000 fulltime students, and include both public and private institutions. As explained previously, our analysis did not restrict the amount of PV for universities by the availability of rooftop or land area. Rather, in constructing the demand curve for each individual university, we evaluated a quantity of PV up to the amount that would generate $25 \%$ of the annual consumption of electricity from the campus. This is much larger than historically typical installations, which often only provide several percent of a university's annual electricity consumption — but is nonetheless shown here in order to explore PV value across a broad range.

\footnotetext{
${ }^{24}$ Although diverse, the degree to which this portfolio of universities represents the national portfolio was not calculated.
} 
Universities typically have large demand charges, so the marginal value of additional PV is high for initial smaller sized systems. Because of their large electricity use, universities have potential to benefit from larger PV systems, but the marginal value of those larger systems is smaller than for the initial smaller systems that reduce demand charges (Figure 16).

Figure 16 (left and right) shows the marginal electric bill savings of additional PV, but the figure shows the bill savings on different scales on the x-axis. Figure 16 (left) plots the curves for all the universities in terms of the actual PV system size. This allows us to compare the relative hosting capacity of universities of different sizes. The points at which the lines end in Figure 16 (left) correspond to the $25 \%$ annual consumption limit mentioned above-for example, the university represented by the yellow curve would generate electricity equal to $25 \%$ of its annual consumption with approximately $1,000 \mathrm{~kW}$ of PV. Some of the universities could host significantly more than the $5,000 \mathrm{~kW}$ shown here, but the plot was truncated for visual clarity. Figure 16 (right) plots each universities' curves in terms of the annual PV generation as a fraction of total electricity consumption. By normalizing for total energy consumption, we can see that the curves are more similar than they appear in Figure 16 (left).
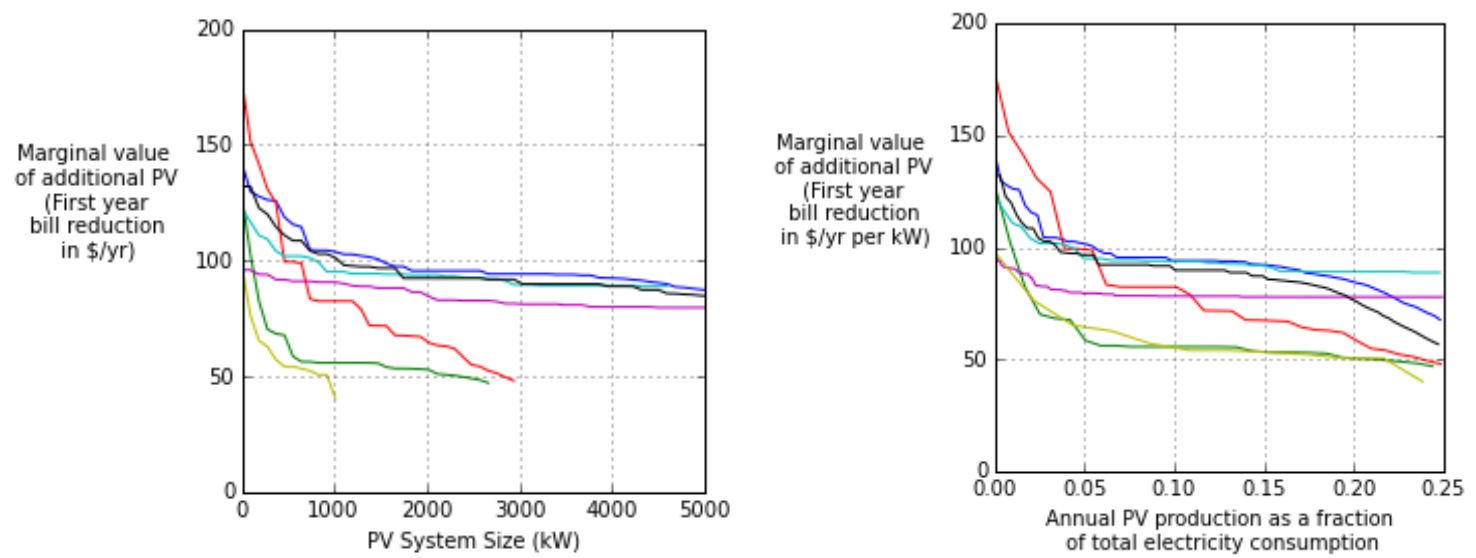

Figure 16. First year electriciy bill savings for seven universities

Note that both these figures show the marginal value of an additional kilowatt of PV capacity, not the average value of all of the installed capacity. For example, for the university represented by the blue line in Figure 16, if the university already has $2,000 \mathrm{~kW}$ of PV, the marginal value of an additional kilowatt of PV would be slightly less than $\$ 100$ in the first year of operation. When considering the value of all $2,001 \mathrm{~kW}$, the average marginal value would be $\$ 109.60$ per kilowatt.

The savings decrease as the system sizes increase because all of these universities are served by tariffs that include demand charges to varying degrees. For the seven universities examined, the PV capacity that achieves the first $5 \%$ energy penetration has significantly greater value due to its more efficient reduction of demand charges (Figure 17). The steep drop in value in those initial $5 \%$ is correlated to the magnitude of each university's demand charge and the initial temporal coincidence between the hour of the original peak demand and peak solar generation. For example, the university represented by the red line has a demand charge of more than $\$ 18 / \mathrm{kW}$ and the original load profile often peaked in the early afternoon. 
Figure 17 shows the value of PV in differnet energy terms from Figure 16-the average reduction of electric bill per kilowatt-hour of PV electricity. For example, if a PV array generates $10,000 \mathrm{kWh}$ in its first year and reduces the electric bill by $\$ 1,000$-including demand charges and energy charges - then the first year average value is $10 £ / \mathrm{kWh}$.

This metric can be used to approximately gauge the relative value of a typical PPA, which often contract for energy in terms of cents per kilowatt-hour. Many universities are unable to monetize the federal tax credits and therefore enter into PPAs with third parties. Note that because this metric is just for the first year, it cannot be used alone to judge the value of a PPA. Assumptions about the forecasted changes in the price of electricity, evolution of electricity tariffs, and any escalation of the PPA price would be necessary to estimate the total lifetime value. The EIA's Annual Energy Outlook and associated data project the changes in the future price of electricity, which can be used as one input in assessing the lifetime value of a PPA.
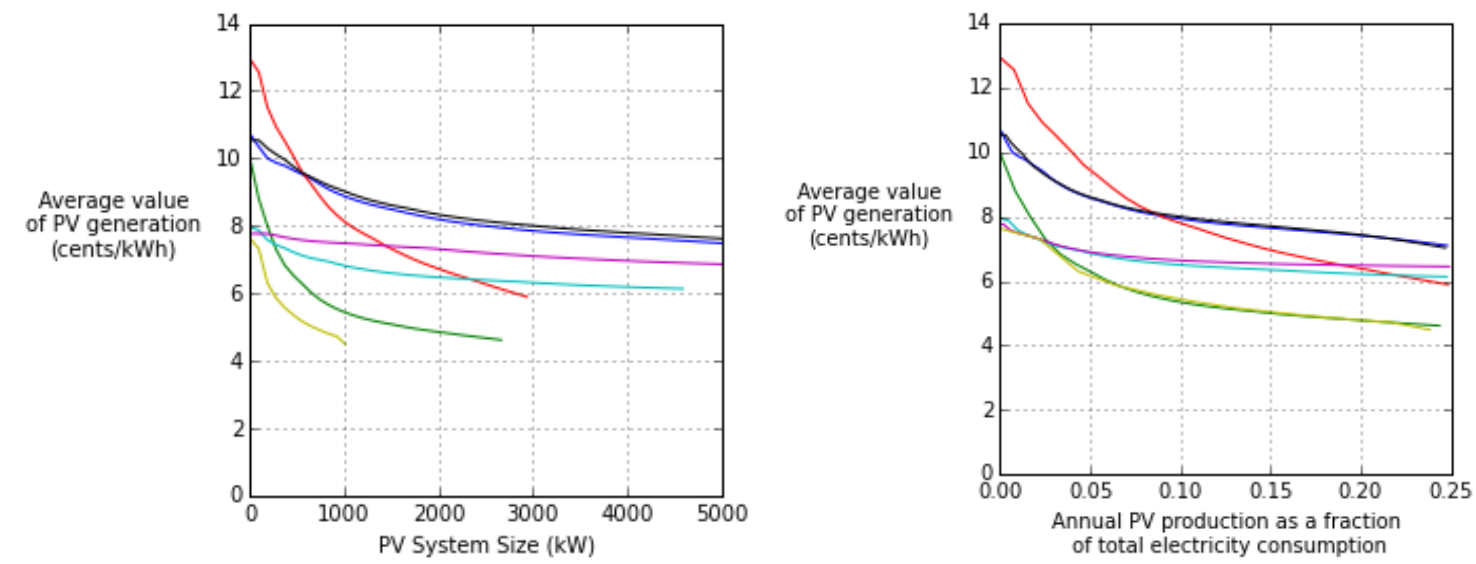

Figure 17. Average PV generation value by system size and fraction of total electriciy consumption for seven universities

\subsubsection{Barriers and Opportunities for PV on Offices}

In this section, we discuss both the barriers and opportunities for PV on office buildings, based in part on interviews with market participants. Figure 18 shows the demand for PV on office buildings broken down by the size of the building. The curves are derived from the same analysis as described in Section 3. 


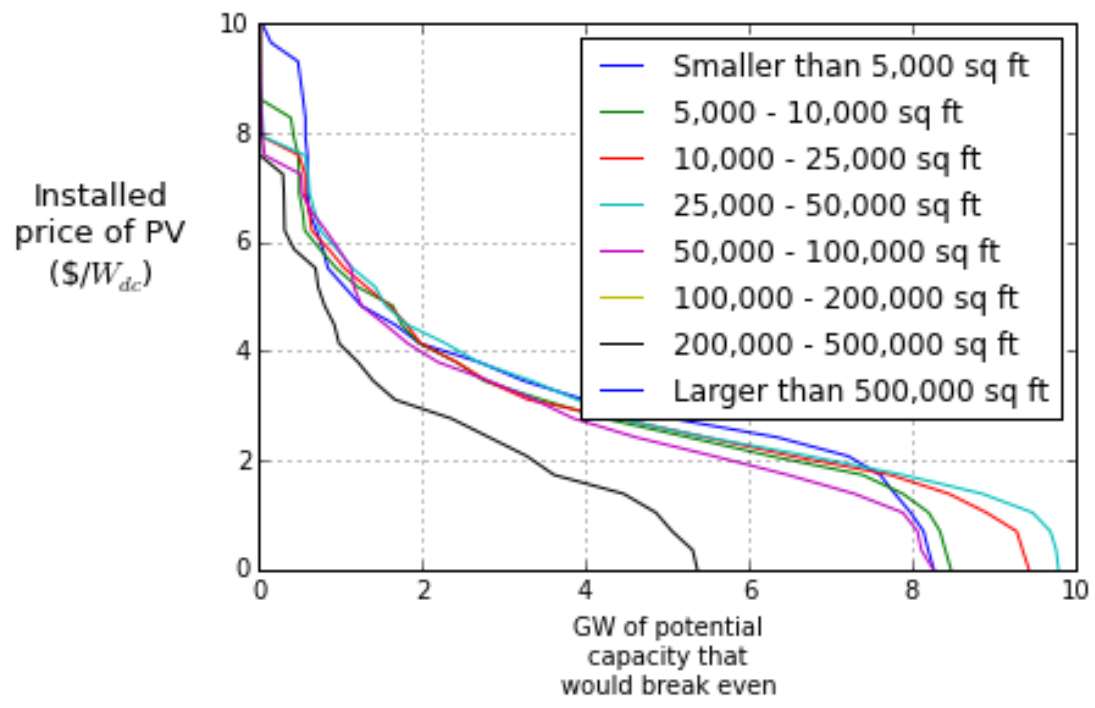

Figure 18. PV demand curve for offices, by office size

In offices, the technical potential of these (essentially arbitrary) size bins are all approximately the same. For example, offices from 5,000-10,000 square feet of floor space have approximately the same technical potential of rooftop PV as offices that have between 100,000 and 200,000 square feet of floor space.

Opportunities: Office buildings can be an attractive option for distributed PV for a number of reasons, including favorable economics and, in some cases, tenants with an interest in sustainability.

- Office buildings typically have a consistent load, significant energy demands during the day due to steady cooling loads, and can have high demand charges, depending on the region. Therefore, the economics of PV can be fairly attractive. There are also opportunities for increasing demand charge savings by pairing solar with load management technologies, such as solar load controllers or storage.

- Some tenants desire a sustainable work space. Office building owners may be able to recoup the cost of PV and other sustainability measures by charging higher rent for a sustainable work space.

- Solar procurement may be of interest for office buildings interested in obtaining LEED certification.

- Compared to other building types, the use and ownership of office buildings or office parks typically remains relatively stable over time, matching the lifetime of the PV system more closely.

- Offices located in technology centers or office parks outside of downtown areas or urban centers generally have fewer siting and permitting restrictions and often more room for installing PV. 
- A relatively untapped opportunity for solar is for a developer to aggregate purchases by multiple office tenants and construct an offsite solar array. However, this would require a virtual net metering arrangement, which is only available in limited jurisdictions.

Barriers: Many of the barriers common across the midscale market can pertain to office buildings. Some of the barriers that are specific to certain types of office buildings or ownership arrangements are discussed below.

- Limited roof space is a common challenge across office buildings. Often, it is not possible to develop a large enough roof-mounted PV system to cover a significant fraction of building load and make the system economic. For tall offices and high-rises in particular, access to the roof is an additional challenge, as well as permitting difficulties in large cities and downtown areas. HVAC systems located on the roof of office buildings can reduce available space for siting PV systems, while shading from other office buildings can also be a concern.

- In some cases, larger systems can be developed on a parking garage, but the additional steel and construction required adds cost. Ground-mounted systems are typically the most economic if there is space, such as within an office park. Overall, the suitability of site is very important and can vary substantially across office buildings.

- The split incentive associated with tenants and landlords is a common barrier for office buildings.

- Screening prospective office buildings can also be challenging for installers because of the time required to determine whether a building is individually or master-metered. This often involves talking to the property management company and then reaching a contact at an investment bank that owns the building.

- Load for individual tenants is often not sufficient to support a large enough system to make installation and financing viable (often projects $250 \mathrm{~kW}$ or larger are preferred).

- Transaction costs and negotiations can be substantial when siting PV on office buildings. Generally, standard forms are not used because building owners have specific issues and concerns. Further, many office building owners have limited experience with solar, which makes negotiations more time consuming for installers.

\subsubsection{Barriers and Opportunities for PV on Hotels}

In this section, we discuss both the barriers and opportunities of PV on hotels. Additionally, Figure 19 shows the demand for PV on hotels broken down by the size of the building. The curves are derived from the same analysis as described in Section 3. 


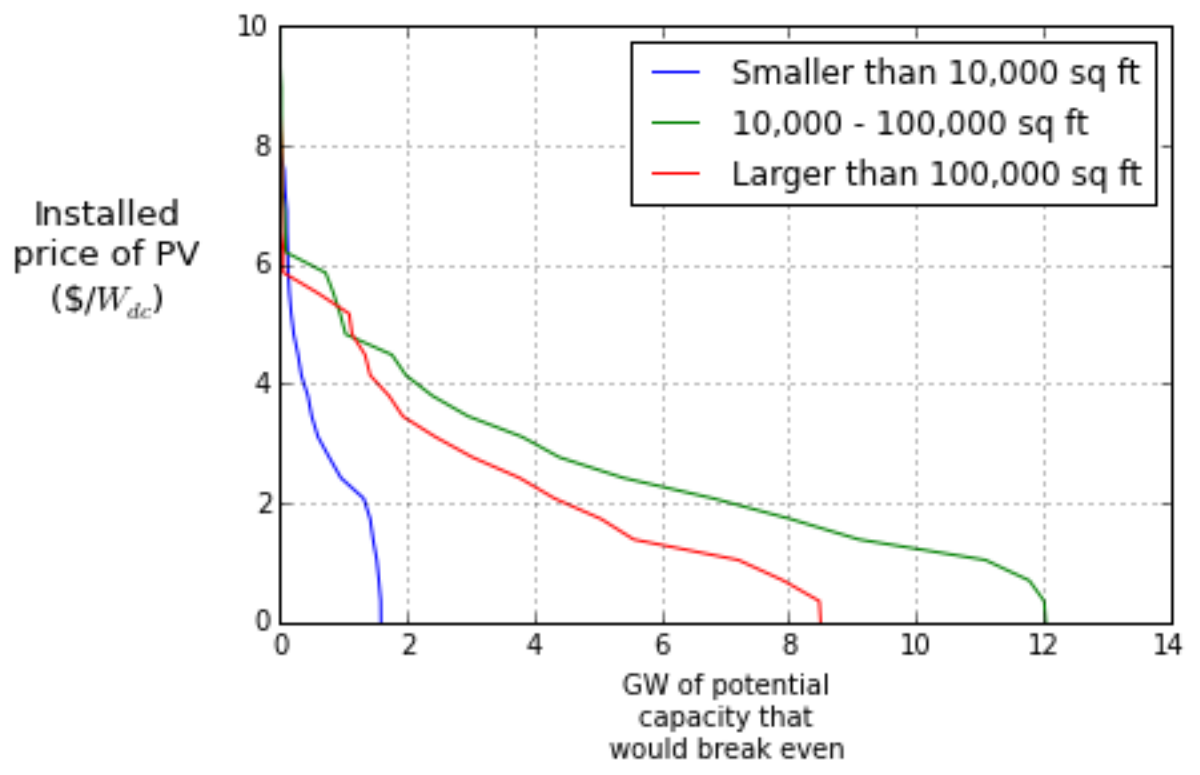

Figure 19. PV demand curve for hotels, by hotel size

Figure 19 shows that of the $22 \mathrm{GW}$ of total technical potential on hotels, a little over half of it is on midsized hotels with 10,000-100,000 square feet of floor area. The curves show a steeper decrease in potential capacity with increasing price as compared to offices, which reflects the relatively poor coincidence of PV generation and the electricity consumption of our simulated hotels. Due to the limited ability of PV to reduce demand charges on hotels, the highest value PV on these buildings is substantially lower than what was observed on offices or warehouses. Nonetheless, a moderate proportion of potential capacity would break even at current prices.

Opportunities: Generally, hotels and offices have similar barriers and challenges, although there are a few distinct considerations for hotels. Unique benefits of hotels, relative to offices and other commercial buildings, include:

- Hotels have one off-taker, as opposed to multiple tenants typically in office buildings, which simplifies the transaction.

- Hotels are consumer-facing and can tell their customers about their sustainability efforts and the benefits of using solar energy. Many hotels have sustainability or green programs, and solar is one way of achieving sustainability goals (Navigant Consulting 2015b).

- Hotels often have consistent usage across weekends and weekdays, which means they can often host larger systems before exporting energy to the grid. However, often the peak demand at hotels occurs in the evening and is not well aligned with solar output, making it more difficult to achieve demand charge savings.

Barriers: Considerations of site suitability are similar to offices, although hotels have some unique challenges with respect to building ownership structures and turnover in ownership. Key challenges for siting PV on hotels include:

- Hotels often have a franchise or LLC structure, which makes financing more difficult. Having multiple parties involved in the transaction adds significant complexity (Navigant 
Consulting 2015b). If the end user is interested in installing PV, they also have to convince the franchise owner, who will also need to sign the contract. The ease or difficulty in reviewing the deal can influence the viability. In some instances, the end users do not have sufficient legal expertise to negotiate contracts and rely on corporate legal staff to help negotiate contracts.

- Credit issues can be a significant challenge for hotels, particularly for third party-owned PV systems. Hotel revenue streams can vary because of seasonal differences in occupancy, which could lead to a risk of intermittent payments. PPA structures require a credit-worthy entity with a deep balance sheet, so typically the parent corporation is involved directly in the contract to satisfy credit requirements (Navigant Consulting 2015b).

- Hotels tend to change owners and operators with some frequency because hospitality companies are primarily in the real estate business and assets are purchased and sold on a regular basis, with an average turnover of 8-9 years (Navigant Consulting 2015b). This makes solar investments riskier because the lifetime of the PV system could span multiple owners. Hospitality companies generally find lengthy contracts to be onerous and often do not evaluate projects longer than a 10 -year period.

- Similar to offices, roof space typically limits PV system sizing, unless there is a parking garage; ground-mounted systems are not typically an option. Site suitability is a significant issue. Considerations about available roof space, access, and obstructions are similar to those identified for offices.

- Hotels may have additional requirements, such as insurance considerations because of having guests on the premises, which can drive up transaction costs. Some hotels have also been built to allow additional floors to be added; in those cases, solar is not preferred. Each property has unique issues, and agreements need to be modified for each location, which adds time and legal expense. 


\subsubsection{Barriers and Opportunities for PV on Warehouses}

In this section, we discuss both the barriers and opportunities of PV on warehouses. Figure 20 shows the demand for PV on warehouses broken down by the size of the building. The curves are derived from the same analysis as described in Section 3.

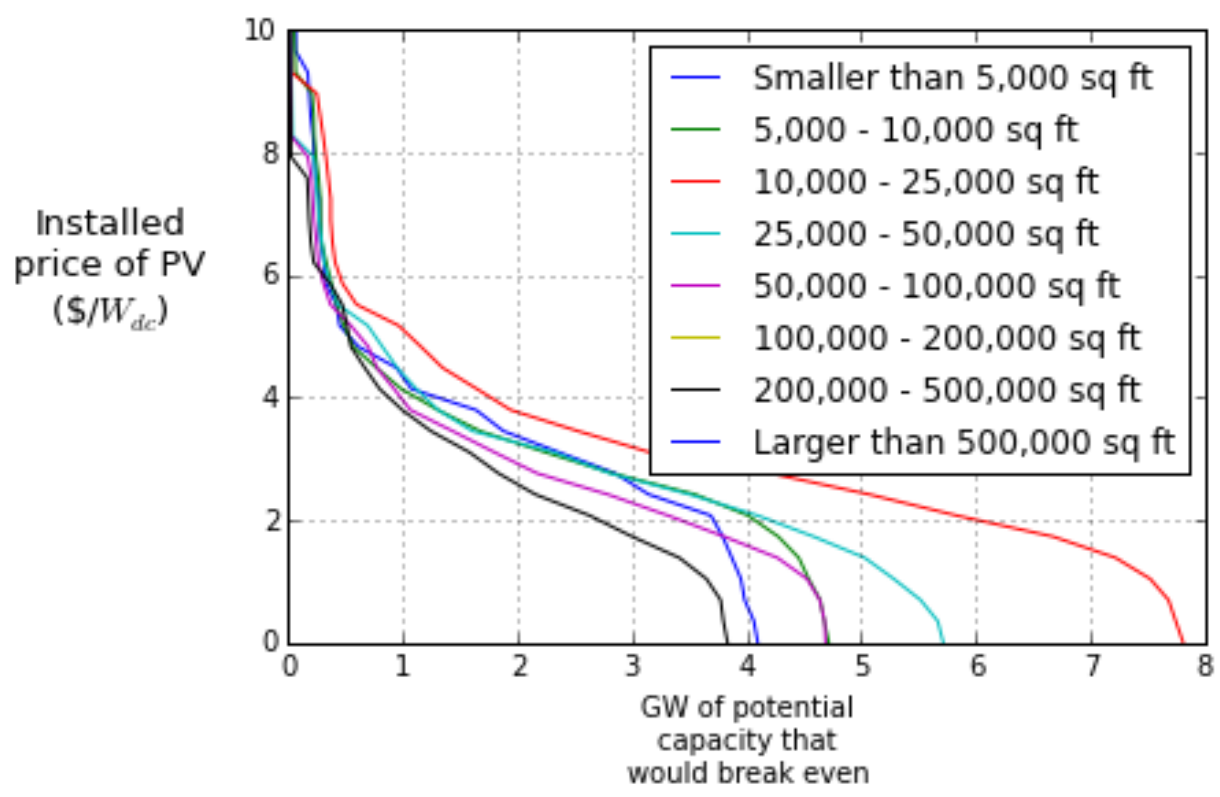

Figure 20. PV demand curve for warehouses, by warehouse size

Warehouses of all sizes have a portion of their technical potential that is relatively high value (Figure 20). As with other buildings, this represents a scattering of PV systems designed to offset several percent of their host building's load. As described in Section 4, this initial capacity is the most efficient at decreasing demand charges, and is therefore the most valuable.

Opportunities: Warehouses have distinct advantages in terms of building structure and roof size that make them distinct from offices and hotels. The following are some of the key advantages of siting PV on warehouses.

- Warehouses often lead to the best economics for PV installations among commercial buildings because of the relatively large roof area and lack of obstructions. For these reasons, there may be substantial opportunity for growth in this market segment.

- Warehouses may have larger loads to serve with the PV system, although energy consumption can vary substantially depending on the type of warehouse. Often warehouses with air conditioning or refrigeration loads have load profiles to support PV installations; in other cases, loads may be small relative to the PV system that can be accommodated on the roof.

- Owner-occupied warehouses, in which the owner consumes the power, likely provide the largest opportunity for installations because there are no landlord/tenant challenges.

- Warehouse owners are often educated energy buyers, which can make transactions easier. 
- In jurisdictions where there is a rooftop feed-in tariff (FIT) program available, owners can lease the warehouse roof for PV installations. One issue is whether the lease payment for the system is attractive enough for the warehouse owner.

- In cases where a change in building ownership is expected during the lifetime of the PV project, the use of PACE financing could address concerns by enabling the loan to be transferred with the building.

Barriers: While warehouses are often good candidates for utilizing solar energy, they may also face a number of barriers, many of which are common to other building types.

- Structural issues, in terms of whether the roof is capable of supporting a large PV system, can be a consideration for systems mounted on warehouses.

- The ratio of building load to PV production can be a concern for warehouses with relatively low loads. In some cases, there is not enough electricity consumed by the warehouse itself to utilize all of the PV production. This raises the question of whether to install a smaller PV project or not.

- Some warehouses are owned by REITs, who may only own the building for a short time (3-5 years) relative to the lifetime of the PV system, which can create a barrier to third-party owned systems in particular because of the need to transfer the contract.

- Similar to other midmarket projects, transaction costs can be significant and contract negotiations can be substantial relative to the project size. Counterparties are sophisticated energy users, but may not have significant experience with solar energy.

\subsubsection{Barriers and Opportunities for PV at Universities}

Opportunities: Universities are substantially different than office buildings and hotels, with distinct hurdles and advantages for development of PV projects. The following are some of the key advantages of siting PV on university campuses.

- Universities may own a substantial amount of land, which can be advantageous for siting and building PV projects. It can also potentially enable the installation of ground-mounted systems, which often have more favorable economics. In some instances, universities may be able to lease land to the developer in exchange for a lower PPA price for a PV system.

- Often universities are large energy users and there are sufficient loads to justify fairly large renewable energy projects.

- Many universities have sustainability initiatives in place, but many have not yet tapped opportunities in solar energy. Often there is widespread interest within the administration and faculty to improve sustainability and maintain an image of a sustainably-operated institution. Students are also often interested in driving clean energy projects.

- Onsite renewable energy projects may offer research opportunities for faculty and students and curriculums can be developed to take advantage of projects located on or near campus. In some cases, universities may be able to support projects with longer payback periods if the project has additional benefits, related to research and student engagement on campus. 
- Universities may have access to lower cost capital, either through use of a green revolving loan fund, student fees, or use of an endowment, though the magnitude of the federal ITC often discourages host ownership of systems. Use of endowment funds to date has been minimal but they would (1) provide capital to finance a solar system, and (2) provide an investment opportunity to a bond or treasury but with potentially higher rates of return.

Barriers: While universities are often good candidates for using solar energy, they also have a number of barriers that are unique to their institutional structure and operating practices.

- Campuses often have a variety of stakeholders involved in the decision-making process and can have complex decision-making structures. The decision to invest in solar energy may require buy-in from multiple committees and administrative offices, which can make the approval process time-consuming. It can be challenging to get approval and buy-in for capital improvements and investments that are not core to the university function. For example, a PV project might need to compete against core facilities such as a new library or department building. Often this means that universities are only willing to purchase power at guaranteed savings from current rates.

- Administrative and procedural barriers can be significant. In some states, capital projects may have to go through separate state commissions that evaluate project economics, which can be a time-consuming process. State budget processes and funding availability can also delay projects.

- Often, universities have specific procurement requirements that preclude them from solesourcing projects. The need to issue public requests for proposals (RFPs) requires longer lead times in developing projects and slows the development process.

- Universities, as nonprofit entities, often prefer to utilize PPA structures to be able to take advantage of federal tax incentives. However, some states do not allow PPAs with third parties. In addition, some schools may not have investment-grade credit to enable them to enter into a PPA agreement. Some universities are partially funded from state appropriations, which can introduce budgetary risks in the event that there are state budget cuts, which could impact their ability to pay third-party contracts.

- Issues surrounding REC ownership can be challenging for universities. Often the sale of RECs is important for enabling project finances to pencil out, but the university needs to retain RECs to make claims about the project and to meet carbon goals. Often, there is confusion about these issues, particularly among project decision makers.

- While universities may have significant amounts of land, land may already be dedicated to future buildings or campus expansions.

- Financing of PV systems may differ from other infrastructure projects, which may pose challenges in gaining project approval. For example, university CFOs may not have experience with long-term contracts with third parties and may need education about the benefits (e.g., the hedge benefits of not being exposed to market prices for energy). Universities sometimes have cogeneration facilities on site, which can make PV pricing less attractive. 


\section{Strategies for Growing the Midscale Market}

This section explores ways of encouraging growth in the midscale solar market and addressing key barriers identified in Section 4. Options discussed below for expanding the market are derived in part from recommendations made by stakeholders active in the midscale solar market during interviews.

\subsection{Contracting Options and Innovations}

One of the most significant barriers to adoption of solar in the midscale market is the split incentive for the tenant and landlord, where the tenant pays for electricity, but the building owner is responsible for capital investments and maintenance. Another key issue is the difference in time frame of PV project financing and the typical length of commercial real estate lease agreements. The following are procurement options that consider these issues. First, we look at options when the building owner owns or contracts for the PV, followed by tenant contracts.

\section{Building owner options-Building} owners can opt to either own the PV system or enter into a PPA agreement with a third party for the energy.

1. In cases where the building owner has a gross lease and is responsible for utility bills, the building owner may be interested in owning or contracting for PV.

2. For situations in which the building owner is responsible for electricity use only in common areas, an option is to size the PV electricity for the common areas.

3. One potential new approach, under a net lease situation where the tenant pays for electricity, is to have the building owner sell the PV electricity directly to tenants under a PPA (between the landlord and tenant). This may be feasible, if allowed under state law, but has not been found to be implemented yet (Navigant Consulting 2015b).

\section{Types of Building Leases}

Under a gross lease, the building owner pays for property taxes, insurance, and maintenance, and may or may not include utility bills. Gross lease arrangements may lead to situations where the building owner enters into the contract for the PV system.

A single net lease is a contract in which the tenant pays for rent and property taxes.

A double net lease is a contract in which the tenant pays rent, property taxes, and insurance.

Under a triple net lease, the tenant pays rent as well as other costs of the property such as property taxes, insurance, maintenance, and operating expenses. Under a triple net lease arrangement, the tenant may be interested in the contractual arrangement with a third party solar provider.

A green lease is a special type of lease agreement that incorporates energy use, water efficiency, waste reduction, renewable energy, and other sustainability goals in the transaction

Source: Navigant Consulting 2015b 
4. Another potential new approach is to structure a PPA with the building owner that addresses the risk of tenant turnover and vacancy rates. For example, in a multitenant shopping center, the building owner takes into consideration the risk that the building is not always $100 \%$ occupied when establishing tenant leasing rates. A solar PPA investor could do something similar. The building owner may be able to take into consideration the risk of empty space in providing the electricity to tenants, for example, under a gross lease arrangement where electricity is included in the lease.

5. To address the mismatch between the length of building ownership and the PV system 20-plus year lifetime, the ability to transfer ownership of the asset or PPA is necessary to address risk. PPA's typically include early buy-out provisions to address this.

Alternatively, transfer can be achieved under a commercial PACE program because repayment remains with the building, not the building owner, as discussed below.

Tenant options - Tenants can enter into a PPA agreement with a third party for the energy. In these instances, the tenant and third-party developer can negotiate an easement with the building owner or a roof lease payment to compensate the owner for participation in the project.

1. In cases where there is a triple net lease or a green lease ${ }^{25}$ and the tenant is responsible for the electricity bills, contracting directly with the tenant for the electricity off-take may be the most viable approach.

2. To address the mismatch between the PV project lifetime and the building lease, tenant PPA agreements are often structured to match the length of the building lease agreement (Navigant Consulting 2015a). Other potential new approaches are to transfer ownership of PPAs to a new tenant, with the building owner playing a backstop role. Another possibility, in regions with competitive wholesale power markets, developers may be able to sell solar power into the wholesale power market if an off-taker leaves. This might help reduce risks, but would likely generate revenues less than from the PPA contract.

\subsection{Alternative Financing Mechanisms for Midscale Market (PACE and FITs)}

Property-assessed clean energy (PACE) financing initiatives hold promise for enabling the expansion of midmarket solar by addressing a number of key concerns. Under a PACE program, a property owner can purchase or contract for a PV system and repay the costs through a special assessment on their property taxes. PACE can be useful for both hosted-owned systems as well as third-party financed systems.

One advantage of PACE for commercial-scale solar projects is that the PV loan is tied to the property, rather than the occupant, providing a convenient mechanism for addressing differences in the PV system lifetime and shorter building lease terms. Other advantages of PACE for commercial-scale systems are that the repayments:

- Are non-recourse, meaning that they do not impact the tenant's creditworthiness

\footnotetext{
${ }^{25}$ For more information on green leases, see the California Sustainability Alliance, http://sustainca.org/green_leases_toolkit/what_green_leasing, accessed September 19, 2016.
} 
- Do not require that the asset be paid in full in case of foreclosure or bankruptcy

- Have interest payments that are tax-deductible

- Generally have terms that are below the current cost of capital for building owners

- May be considered an off-balance-sheet form of financing for the property owner, depending on accounting practices (Mendolsohn 2016).

PACE programs can be developed in states where enabling legislation has been adopted and where a municipality or county implements a program, in conjunction with private lenders. To date, PACE funded projects exist in 14 states, with 32 states plus Washington, D.C. having adopted statutes that enable municipalities and counties to provide PACE for commercial properties (PACEnation 2016). Once challenge with PACE is that there is not a standard PACE program; while programs may have common elements, each program is unique to its jurisdiction.

Feed-in tariff programs, such as those implemented by Southern California Edison (SCE) and Los Angeles Department of Water and Power (LADWP), can also help drive commercial-scale projects. These can help simplify transactions and contracting issues by enabling the PV system owner to sell the generation to the utility under the terms of the FIT. This can be particularly advantageous for building with a large amount of available roof space and no off-taker for the energy, such as warehouses that may not have sufficient loads to absorb the PV generation. FITs are available in a limited number of states, however. In cases where FITs and net metering are not available, building owners could also explore the option of selling the PV project output directly to the utility or into the wholesale electricity market.

\subsection{Aggregated Bidding}

Another approach for building owners is to undertake an aggregated bidding process to obtain competitive solar installation bids. This can help reduce transaction costs across a larger group of installations. For example, a group of building owners, such as schools or universities, could develop an RFP process to solicit PV installation bids that includes a standard contract. PV installers would bid prices and any exceptions to the contract. This type of contract standardization and larger bidding processes can help keep installation prices low.

The New York Power Authority (NYPA) conducted a competitive procurement on behalf of interested K-12 schools under New York's K-Solar program. NYPA issued an RFP and selected a winning bidder, after which individual school districts could enter into a contract with the selected bidder. This collaborative procurement results in lower transaction costs for each K-12 school as well as a very competitive solar price. NYPA was able to established a guaranteed cost savings mechanism for the PPA compared to retail rates, with a true up every five years (New York State Education Department 2015).

Similarly, the Council of Independent Colleges of Virginia developed a group purchasing model, issuing an RFP for $37 \mathrm{MW}$ of solar at 16 colleges. The RFP included four bundles of sites; bidders could bid on one or several bundles. Vendor selection is anticipated in fall 2016. 


\subsection{Expansion of Access to PPA Options}

For tax-exempt entities, who are not able to directly take the federal ITC, third-party PPA agreements are the most viable alternate to developing cost-effective projects that utilize all available incentives. Third-party PPAs can offer a number of other advantages in that they can result in positive cash flows immediately, costs are predictable over the lifetime of the agreement (which can reach 15-20 years), the third party takes responsibility for installation and operations and maintenance, risks of less than anticipated output are borne by the third party, and contracts with a third party are not on the company's balance sheet. Therefore, these contracts do not limit the amount of debt that a company can incur (Feldman and Bolinger 2016).

While PPAs are allowed or in use in 24 states and Washington, D.C., seven states disallow their use, and it remains unclear whether they can be used in the remaining states (DSIRE 2016). In some states, there are limits on system size or limitations on use in certain sectors. States that have disallowed these types of agreements typically do so because they may not conform to the states definition of a "utility" or that they can result in an unregulated utility selling power (Kollins et al. 2010).

\subsection{Increased Metering and Locational Siting Flexibility (Virtual Net Metering and Community Solar)}

Virtual net metering could help facilitate midscale market PV projects, particularly development of ground mounted systems, by eliminating barriers related to available installation space and short term leases. Virtual net metering can facilitate projects where onsite access is limited or rooftop systems are precluded because of the age of the roof, obstacles, or other barriers.

Enabling multiple facilities to utilize the output of a larger ground-mounted system can reduce development barriers and enable larger projects to be constructed to take advantage of economies of scale.

Currently, 14 states and Washington, D.C. have some form of virtual net metering or community solar policy (Center for Sustainable Development 2015). ${ }^{26}$ In some states, eligibility is offered in limited cases, for example, in California, virtual net metering is restricted to multitenant buildings, though utilities in the state are also launching community solar programs. In New York, for example, Bloomberg is using the state's remote net metering policy to source solar from a 1.5-MW solar array at the JFK Airport Park for its midtown Manhattan skyscraper and other buildings (Bloomberg 2015). The policy allows Bloomberg to source a greater amount of solar than could be supported by building infrastructure.

Community solar options provide a similar function to virtual net metering, allowing the output of a single PV project to be shared by multiple off-takers. Community solar programs are offered by utilities or third parties in states or utility service territories where the utility or third party is allowed to enable customers to purchase solar who may otherwise not be able to due to roof constraints or other barriers. Where this exists, the building owner may be able to install the PV system and sell the power to the community solar program. Alternatively, building owners and

\footnotetext{
${ }^{26}$ States with virtual net metering or community solar supportive policies are California, Colorado, Connecticut Delaware, Maryland, Massachusetts, Minnesota, New Hampshire, New York, Oregon, Vermont, Washington, and Washington, D.C.
} 
tenants may prefer to procure energy through community solar programs instead of installing a system on site.

\subsection{Data Transparency}

Greater data transparency on master-metered buildings could also lower customer acquisition costs, facilitating growth in the midscale market. Developers need to understanding how the building is metered and whether data are available for common areas and individual tenant spaces in order to assess project potential. If developers need to spend extra time gathering this data, from tenants, building operators, and/or building owners, their costs increase. Limited commercial real estate datasets exist currently, but more detailed data and wider availability could help facilitate the screening process and enable developers to hone in on the most viable projects more easily.

\subsection{Targeted Education Efforts}

Many entities in the midsize market are not fully familiar with solar energy options, cost reductions that have been achieved in recent years, and the ease of installation of solar. Educational materials and unbiased information provided by neutral entities, rather than market participants, can be important for end-users who want to develop a clear understanding of the marketplace and installation considerations in order to make informed procurement decisions.

Efforts could be made to educate key market segments about the potential for expanded adoption, including information on solar energy procurement options, costs, contracting methods, environmental benefits, and installation issues. This could include educational efforts and campaigns coordinated by governmental organizations in conjunction with trade organizations or non-governmental organizations (NGOs) that work with various market segments, such as organizations that focus on sustainability issues for hotels, universities, or real estate developers.

Some potential target audiences for additional educational efforts could be:

- The Hospitality Industry, including large hotel chains: This market segment in particular has a relatively strong interest in sustainability, as evidenced by a relatively large number of trade associations and organizations that focus on sustainability issues (Table 3). Partnerships could be developed between governmental entities and existing trade groups, particularly those with a sustainability focus, to educate this segment about reductions in the cost of solar, financing options, siting, and other considerations for evaluating PV installations.

- $\quad$ Real Estate Investment Trusts (REITs) and real estate developers: This segment of the market is particularly important because of its reach and the fact that are large fraction of the midmarket buildings are owned by REITs. Educational efforts could be undertaken by governmental organizations working through or in conjunction with real estate trade associations or sustainability organizations (Table 3 ). In addition to educating this audience, additional clarity is needed from the IRS about whether REITs can install solar and not jeopardize their tax status.

- Universities: While educational efforts have been underway in this sector, the large number and geographic spread of universities may warrant continuing efforts. Like hotels, 
universities have a large number of trade associations or university consortiums that focus on sustainability. Continued outreach efforts could leverage efforts by these groups and focus on educating university staff about solar energy options, onsite versus offsite issues, and system ownership versus the use of third-party suppliers to take advantage of tax credits.

Table 3. Selected Sustainability Associations for Building Segments

\begin{tabular}{|c|c|c|}
\hline & Association/Organization & Description \\
\hline \multirow{7}{*}{ 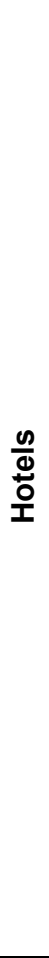 } & $\begin{array}{l}\text { The American Hotel \& Lodging Association } \\
\text { (AH\&LA) } \\
\underline{\text { ahla.com }}\end{array}$ & $\begin{array}{l}\text { AH\&LA's comprehensive Green Resource Center offers } \\
\text { guidelines, best practices, industry suppliers, and other tips } \\
\text { for becoming a more eco-friendly organization. }\end{array}$ \\
\hline & $\begin{array}{l}\text { Global Sustainable Tourism Council } \\
\text { gstcouncil.org/en/ }\end{array}$ & $\begin{array}{l}\text { Establishes and manages global sustainable standards } \\
\text { with the aim of increasing sustainable tourism knowledge } \\
\text { and practices among public and private stakeholders }\end{array}$ \\
\hline & $\begin{array}{l}\text { Green Hotelier } \\
\text { greenhotelier.org/about-us/ }\end{array}$ & $\begin{array}{l}\text { A project of the International Tourism Partnership, Green } \\
\text { Hotelier works with hotel companies to drive the } \\
\text { responsible business agenda. Through ITP, Green Hotelier } \\
\text { reaches } 24,000 \text { hotel properties in over } 100 \text { countries. }\end{array}$ \\
\hline & $\begin{array}{l}\text { Green Lodging News } \\
\text { greenlodgingnews.com }\end{array}$ & $\begin{array}{l}\text { A leading environmental news source, it provides a } \\
\text { resource for current industry articles and product features. }\end{array}$ \\
\hline & $\begin{array}{l}\text { Rainforest Alliance } \\
\text { rainforest-alliance.org/tourism/training }\end{array}$ & $\begin{array}{l}\text { Works with major local and international tour operators } \\
\text { around the world to promote ecologically and socially } \\
\text { responsible best practices for tourism businesses in Latin } \\
\text { America }\end{array}$ \\
\hline & $\begin{array}{l}\text { Sustainable Travel International } \\
\text { sustainabletravel.org }\end{array}$ & $\begin{array}{l}\text { Provides accommodations with a suite of solutions that } \\
\text { help them to understand, monitor, report on, and improve } \\
\text { performance across key sustainability indicators. }\end{array}$ \\
\hline & $\begin{array}{l}\text { The Travel Foundation } \\
\text { thetravelfoundation.org.uk/green_business tools/ }\end{array}$ & $\begin{array}{l}\text { Provides comprehensive advice for accommodation } \\
\text { providers who would like to green their property }\end{array}$ \\
\hline \multirow{6}{*}{ 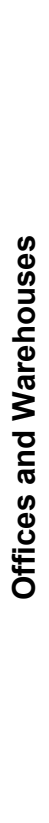 } & $\begin{array}{l}\text { Association of Green Property Owners \& } \\
\text { Managers (AGPOM) } \\
\text { agpom.org }\end{array}$ & $\begin{array}{l}\text { AGPOM is for commercial real estate, multifamily and } \\
\text { hospitality properties and primary focuses on raising } \\
\text { awareness of the connection between "green" practices } \\
\text { and reduced property risks. }\end{array}$ \\
\hline & $\begin{array}{l}\text { BOMI } \\
\text { bomi.org/agpom.aspx }\end{array}$ & $\begin{array}{l}\text { A nonprofit, independent educational institute that aims to } \\
\text { fulfill the need for a higher level of training and expertise in } \\
\text { the property and facility management profession }\end{array}$ \\
\hline & $\begin{array}{l}\text { Distribution Business Management Association } \\
\text { (DBMA) } \\
\text { dcenter.com }\end{array}$ & $\begin{array}{l}\text { DBMA provides think tank forums between business and } \\
\text { academia that seek solutions to the pressing issues facing } \\
\text { today's and tomorrow's supply chain and logistics } \\
\text { executives. }\end{array}$ \\
\hline & $\begin{array}{l}\text { Greenbiz } \\
\text { greenbiz.com }\end{array}$ & $\begin{array}{l}\text { Works to harness the power of technology to bring } \\
\text { environmental information, resources, and tools to the } \\
\text { mainstream business community }\end{array}$ \\
\hline & $\begin{array}{l}\text { NAIOP Commercial Real Estate Development } \\
\text { Association } \\
\text { naiop.org }\end{array}$ & $\begin{array}{l}\text { Provides networking opportunities, educational programs, } \\
\text { research on trends and innovations and strong legislative } \\
\text { representation. }\end{array}$ \\
\hline & $\begin{array}{l}\text { U.S. Green Building Council } \\
\text { usgbc.org }\end{array}$ & $\begin{array}{l}\text { USGBC is committed to transforming the way our buildings } \\
\text { are designed, constructed, and operated through LEED. }\end{array}$ \\
\hline
\end{tabular}




\begin{tabular}{|c|c|c|}
\hline & Association/Organization & Description \\
\hline \multirow{5}{*}{ 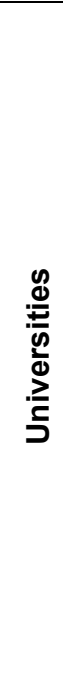 } & $\begin{array}{l}\text { The Association for the Advancement of } \\
\text { Sustainability in Higher Education (AASHE) } \\
\text { aashe.org/about }\end{array}$ & $\begin{array}{l}\text { Empowers higher education faculty, administrators, staff, } \\
\text { and students to be drivers of sustainability innovation }\end{array}$ \\
\hline & $\begin{array}{l}\text { Second Nature } \\
\text { secondnature.org }\end{array}$ & $\begin{array}{l}\text { Works with colleges and universities to help make the } \\
\text { principles of sustainability fundamental to every aspect of } \\
\text { higher education }\end{array}$ \\
\hline & $\begin{array}{l}\text { Green Gigawatt Challenge } \\
\text { http://greengigawatt.org/about.php }\end{array}$ & $\begin{array}{l}\text { An effort to catalyze } 1 \mathrm{GW} \text { of green power by } 2020 \text { by } \\
\text { providing support to help campuses enter into large scale } \\
\text { PPAs }\end{array}$ \\
\hline & $\begin{array}{l}\text { The National Association of College and } \\
\text { University Business Officers (NACUBO) } \\
\text { nacubo.org/About NACUBO.html }\end{array}$ & $\begin{array}{l}\text { NACUBO is a membership organization representing more } \\
\text { than } 2,100 \text { colleges and universities across the country. }\end{array}$ \\
\hline & $\begin{array}{l}\text { Solar University Network } \\
\text { solarendowment.org }\end{array}$ & $\begin{array}{l}\text { An initiative of the Midwest Renewable Energy Association } \\
\text { (MREA), which seeks to make solar energy cost- } \\
\text { competitive with other forms of electricity by the end of the } \\
\text { decade }\end{array}$ \\
\hline
\end{tabular}

\subsection{Simplification of Interconnection Processes}

Customer acquisition is a large barrier to midmarket solar, but other processes also hamper the market, adding time and money to projects. Simplifying interconnection processes for midsized behind-the-meter systems can remove a cost and transactional burden for midscale projects. Interconnection costs are highly site specific, largely driven by distance from the substation, distribution system capacity, and PV colocation with other services. In some states, interconnection processes for commercial-scale projects can be similar to that of larger-scale systems, which imposes a burden and cost for the substantially smaller systems. While state interconnection rules vary, efforts could be undertaken to simplify interconnection procedures for behind-the-meter systems, with the rationale that much of the energy is used on site and not fed back into the utility grid; therefore, grid impacts should be negligible.

Potential improvements to interconnection procedures for midscale PV systems include greater cost certainty, fast tracking of interconnection studies, shorter processing times, and adaptable interconnection forms that can be used with third-party financing approaches. For example, to address cost risks for projects seeking interconnection, California established a "cost envelope" approach, where developers have the option to get a $\pm 25 \%$ binding cost estimate (CPUC 2016). In addition, California and some other states, have procedures to fast track impact studies for projects up to $2 \mathrm{MW}$ in size (Ardani et al. 2015).

Adding transparency in the interconnection process could also speed transaction times. Investorowned utilities in California are required to provide online interconnection maps that show key information about the interconnection potential of distributed resources. In Hawaii, Hawaiian Electric (HECO) publishes its interconnection queue online so installers can see where their project is in the queue.

Developing more flexible and adaptable interconnection forms that address various contracting arrangements could also facilitate midscale market PV transactions, by minimizing legal barriers. 


\subsection{Simplification and Standardization of Transactions}

Standardization of contracts and contract terms would help simplify the installation process and reduce transaction costs for midscale PV installations. Commercial PV contracts can be heavily negotiated to satisfy individual end-user circumstances, which can be financially onerous given typical project sizes. The use of standardized contracts, such as those used for mortgages or car purchases, could help reduce costs and the transactional barriers associated with detailed legal negotiations.

- Standardized contracts for commercial and residential systems have been developed by the Solar Access to Public Capital working group, supported by the U.S. Department of Energy, with input from a variety of industry participants. ${ }^{27}$ The working group also created a best practices document for installation and operations and maintenance.

- NREL created an annotated explanation of certain key PPA terms. ${ }^{28}$ Using the K-Solar PPA template, the widget allows users to click on key terms (e.g., "facility access agreement") and see an explanation of that term.

Wider acceptance of standardized contracts for midsized projects could help reduce transaction costs as a barrier.

A standardized method for analyzing credit risk could help with third-party financing agreements in the midscale PV market. One of the key challenges is showing the creditworthiness of the offtaker in order for the third party to get the system financed. There is no standardized credit score or rating for private sector companies in the midscale market, which makes PPA transactions more challenging. Some industry efforts are underway to create a standard method for assessing the risk of commercial and industrial solar projects, in order to make projects more easily financeable. ${ }^{29}$

\footnotetext{
${ }^{27}$ For more information and access to the standardized contracts, see https://financere.nrel.gov/finance/content/solarsecuritization-and-solar-access-public-capital-sapc-working-group\#standard_contracts, accessed August 29, 2016. ${ }^{28} \mathrm{See}$ http://widgets.nrel.gov/financere/interactive-solar-ppa/.

${ }^{29}$ For example, see http://www.trusolar.org/about.html
} 


\section{Summary and Conclusions}

The midscale market has grown more slowly than the residential and utility-scale segments in recent years, with non-residential PV installations representing only $14 \%$ of total installations in 2015. Growth has been more modest for midsize behind-the-meter PV systems (up to $2 \mathrm{MW}$ ) because this market faces a variety of institutional and economic barriers in the form of split incentives between landlord/tenant, siting restrictions, contracting complexities, and transaction costs. However, this market segment is ripe for substantial future growth if key barriers can be addressed.

In this analysis, we examined the market potential for four key segments that hold promise for increased deployment of PV: hotels, offices, warehouses, and universities. At 2015 average (50$100 \mathrm{~kW})$ installed prices $\left(\$ 3.20 / \mathrm{W}_{\mathrm{DC}}\right)$, the techno-economic potential for these market segments is substantial, with $22 \mathrm{GW}$ of PV that could potentially be installed on offices, $15 \mathrm{GW}$ on warehouses, and $6 \mathrm{GW}$ on hotels. These estimates represent the amount of PV capacity that would break even for the system owner, without consideration of institutional barriers or access to financing. ${ }^{30}$ Further price reductions could lead to significantly larger potential because these estimates (based on the 2015 price of PV) represent $37 \%$ of the total technical potential for offices, $41 \%$ for warehouses, and 30\% for hotels. With future price declines on par with the DOE SunShot 2020 targets, the techno-economic potential for these three segments could reach more than $100 \mathrm{GW}$ (16 GW hotels, $34 \mathrm{GW}$ warehouses, $54 \mathrm{GW}$ offices, which corresponds to $73 \%$, $92 \%$, and $89 \%$ of their respective total technical potential).

We estimate that if all universities deployed distributed PV up to a capacity that would generate $25 \%$ of their annual electricity consumption, the total capacity would be slightly greater than $16 \mathrm{GW}$. Of this, $3.7 \mathrm{GW}$ of "high value" capacity exists - capacity that would result in average bill savings greater than $10 \phi / \mathrm{kWh}$. Techno-economic potential estimates for universities were calculated using a different methodology because they are not a building type per se and different data sources were available.

The techno-economic analysis showed that — on average — offices had the highest bill savings per kilowatt of PV installed due to peak load occurring during daylight hours where PV could reduce demand charges. Hotels had the lowest bill savings due to a tendency for peak demand to occur in the evening, and warehouses fell between the two. The economics of PV on universities is strengthened wherever the entire campus is metered together, but the economics are weakened by generally less expensive electricity on campuses. Critically, however, the analysis showed that the value of PV varied significantly within each building segment and it was most strongly driven by the price and structure of the electricity rate to which the building would subscribe.

While institutional and transactional barriers may make it challenging to achieve the full technoeconomic potential estimates, a number of factors on the positive side of the ledger encourage development. For example, many midmarket customers, including corporations, universities, and hotels in particular, have sustainability goals and initiatives. Solar energy procurement is a

\footnotetext{
${ }^{30}$ The analysis assesses siting restrictions associated with roof area, shading and other characteristics, but it does not consider the age of the roof or structural ability of the building to accommodate PV.
} 
relatively untapped additional effort that could fit well within those efforts. Table 4 compares the opportunities and barriers to PV deployment in the four market segments examined here.

Table 4. Comparison of Opportunities for PV Deployment by Market Segment

\begin{tabular}{lcccc}
\hline & Offices & Hotels & Universities & Warehouses \\
\hline $\begin{array}{l}\text { Electricity } \\
\text { Savings Potential }\end{array}$ & 0 & 0 & 0 & 0 \\
$\begin{array}{l}\text { Demand Charge } \\
\text { Reductions }\end{array}$ & 0 & 0 & 0 & \\
$\begin{array}{l}\text { Sustainability } \\
\text { Goals }\end{array}$ & - & 0 & 0 & 0 \\
$\begin{array}{l}\text { Stakeholder } \\
\text { Interest }\end{array}$ & 0 & 0 & 0 & 0 \\
$\begin{array}{l}\text { Ownership } \\
\text { Structure } \\
\text { Building and } \\
\text { Land Availability }\end{array}$ & 0 & 0 & 0 & 0 \\
\hline \begin{tabular}{l} 
Metering \\
\hline
\end{tabular} & 0 & 0 & 0 & 0 \\
\hline
\end{tabular}

To realize substantial growth in the midscale sector in coming years, a number of strategies could be pursued to address key barriers. Based in part on discussions with market participants, options for facilitating increased deployment in the midscale market include the following.

- $\quad$ Policies to Enable Third-Party PPAs: Expanded adoption of policies enabling use of thirdparty PPAs in areas where it is either unclear or not in use would help drive midscale market deployment, particularly for entities unable to monetize federal tax credits. Often, projects are stalled if financing structures cannot utilize the ITC and are required to provide upfront capital.

- $\quad$ Contracting Options: To address split incentives and the mismatch in length of building lease and PV financing terms, some options include triple net leases, where the tenant pays electricity costs, or new ideas such as having the building owner address the risk of tenant turnover in the contract or separate landlord/tenant contracts.

- PACE Financing: PACE financing offers advantages for commercial-scale PV projects including that the PV loan is tied to the property rather than the occupant, which provides a mechanism for addressing differences in the PV system lifetime and shorter building lease terms.

- $\quad$ Feed-in Tariffs: FITs may help simplify transactions and contracting issues by enabling the PV system owner to sell the generation to the utility. This can be particularly advantageous for buildings with a large amount of available roof space and no off-taker for the energy. 
- Policies that Enable Offsite Systems: Wider adoption of virtual net metering could help facilitate midmarket ground mounted systems by eliminating barriers related to available installation space and short term leases. Community solar offers offsite opportunities where site restrictions are significant.

- Educating Key Market Segments: Efforts could be made to team with trade associations and others to educate key market segments about the potential for expanded adoption.

- Transactional Issues: Simplifying_interconnection processes and using standardized contracts and terms for midscale behind-the-meter systems could reduce legal barriers and costs. In addition, a standardized method for analyzing credit risk of private entities in the midscale market could help facilitate use of third-party financing.

In addition to the market segments studied here, the following types of facilities hold potential for significant adoption of PV, based on their relative characteristics: K-12 schools, other municipal government facilities, water districts, hospitals, brownfields, and manufacturing facilities. These types of entities could be targets for educational efforts or could warrant additional techno-economic potential analysis. 


\section{References}

Ardani, K., C. Davidson, R. Margolis, and E. Nobler. 2015. A State-Level Comparison of Processes and Timelines for Distributed Photovoltaic Interconnection in the United States. Golden, CO: National Renewable Energy Laboratory. NREL/TP-7A40-63556. http://www.nrel.gov/docs/fy15osti/63556.pdf.

Barbose, Galen, and Naïm Darghouth. 2016. Tracking the Sun IX: The Installed Price of Residential and Non-Residential Photovoltaic Systems in the United States. Berkeley, CA: Lawrence Berkeley National Laboratory. LBNL-1006036. https://emp.lbl.gov/sites/all/files/tracking the_sun_ix_report.pdf

Blair, Nate, Aron P. Dobos, Janine Freeman, Ty Neises, Michael Wagner, Tom Ferguson, Paul Gilman, and Steven Janzou. 2014. System Advisor Model, SAM 2014.1.14: General Description. Golden, CO: National Renewable Energy Laboratory. NREL/TP-6A20-61019. http://www.nrel.gov/docs/fy14osti/61019.pdf.

Bloomberg. 2015. "Using the Sun to Power Bloomberg's Global HQ and Other Facilities." News release, September 16. http://www.bloomberg.com/company/announcements/using-the-sun-topower-bloombergs-global-hq-and-other-facilities/.

BNEF (Bloomberg New Energy Finance). 2016. "Research Note: US Renewable Energy Offtake Options: Beyond PPAs." July 20.

Bolinger, Mark, and Joachim Seel. 2016. Utility-Scale Solar 2015: An Empirical Analysis of Project Cost, Performance, and Pricing Trends in the United States. Berkeley, CA: Lawrence Berkeley National Laboratory. LBNL-1006037. https://emp.lbl.gov/publications/utility-scalesolar-2015-empirical

Center for Sustainable Energy. 2015. Virtual Net Metering Policy Background and Tariff Summary Report. Accessed September 19, 2016: https://energycenter.org/sites/default/files/docs/nav/programs/solarpathways/(6902)_Virtual_Net_Metering_Policy_Background_and_Tariff_Summary_Report.pdf.

Chung, Donald, Carolyn Davidson, Ran Fu, Kristen Ardani, and Robert Margolis. 2015. U.S. Photovoltaic Prices and Cost Breakdowns: Q1 2015 Benchmarks for Residential, Commercial, and Utility-Scale Systems. Golden, CO: National Renewable Energy Laboratory. NREL/TP6A20-64746. http://www.nrel.gov/docs/fy15osti/64746.pdf.

CPUC (California Public Utilities Commission). 2016. "Order Instituting Rulemaking on the Commission's Own Motion to Improve Distribution Level Interconnection Rules and Regulations for Certain Classes of Electric Generators and Electric Storage Resources." Decision 16-06-052. June 23. http://docs.cpuc.ca.gov/PublishedDocs/Published/G000/M164/K376/164376491.pdf.

Davidson, Carolyn, Pieter Gagnon, Paul Denholm, and Robert Margolis. 2015. Nationwide Analysis of U.S. Commercial Building Solar Photovoltaic (PV) Breakeven Conditions. Golden, 
CO: National Renewable Energy Laboratory. NREL/TP-6A20-64793.

http://www.nrel.gov/docs/fy16osti/64793.pdf.

Devine, Avis, and Nils Kok. 2015. "Green Certification and Building Performance: Implications for Tangibles and Intangibles." Journal of Portfolio Management 7. http://www.corporateengagement.com/files/publication/DK JPM 2015.pdf.

DSIRE. 2016. " 3 rd Party Solar PV Power Purchase Agreement Map, July 2016." http://www.dsireusa.org/resources/detailed-summary-maps/.

EIA (U.S. Energy Information Administration). 2016a. “2012 Commercial Buildings Energy Consumption Survey (CBECS).” Last modified May 17.

http://www.eia.gov/consumption/commercial/.

—. 2016b. "Electric Power Sales, Revenue, and Energy Efficiency Form EIA-861 Detailed Data Files." Released August 2. https://www.eia.gov/electricity/data/eia861/.

EPA 2015. “GPP GP and Solar Use by Industries 2015." Data sent by James Critchfield on October 8, 2016 via email.

Feldman, David, and Mark Bolinger. 2016. On the Path to SunShot: Emerging Opportunities and Challenges in Financing Solar. Golden, CO: National Renewable Energy Laboratory. NREL/TP-6A20-65638. http://www.nrel.gov/docs/fy16osti/65638.pdf.

Gagnon, Pieter, Robert Margolis, Jennifer Melius, Caleb Phillips, and Ryan Elmore. 2016. Rooftop Solar Photovoltaic Technical Potential in the United States: A Detailed Assessment. Golden, CO: National Renewable Energy Laboratory. NREL/TP-6A20-65298.

http://www.nrel.gov/docs/fy16osti/65298.pdf.

Kollins, Katharine, Bethany Speer, and Karlynn Cory. 2010. Solar PV Project Financing: Regulatory and Legislative Challenges for Third-Party PPA System Owners. Golden, CO: National Renewable Energy Laboratory. NREL/TP-6A2-46723.

http://www.nrel.gov/docs/fy10osti/46723.pdf.

Mendelsohn, Mike. 2016. "PACE is Crucial for Growing Commercial Real Estate Solar Markets." Greentech Media, April 25. http://www.greentechmedia.com/articles/read/realizingthe-potential-of-the-commercial-real-estate-solar-markets.

Navigant Consulting. 2015a. Promoting Solar PV on Leased Buildings Guide: Benefits, Barriers, and Strategies. Washington, D.C.: U.S. Department of Energy Better Buildings Alliance. https://betterbuildingssolutioncenter.energy.gov/sites/default/files/attachments/Promoting-SolarPV-on-Leased-Buildings-Guide-.pdf.

- 2015b. On-Site Commercial Solar PV Decision Guide for the Hospitality Sector. Washington, D.C.: U.S. Department of Energy Better Buildings Alliance.

https://betterbuildingssolutioncenter.energy.gov/sites/default/files/attachments/Solar-PVDecision-Guide-For-Hospitality.pdf. 
New York State Education Department. 2015. Memorandum discussing savings provided in the solar PPA template. http://www.p12.nysed.gov/facplan/documents/K-SolarJointSEDNYPAMemo.pdf.

North Carolina Clean Energy Technology Center. 2016. "The 50 States of Solar: Q1 2016 Quarterly Report.”

PACENation. 2016. “Q1 2016 C-PACE Market Update.” New York: PACENation. http://www.pacenation.us/wp-content/uploads/2016/06/Market-update-Q1-2016.pdf.

SEIA (Solar Energy Industries Association). 2015. Solar Means Business 2015: Top U.S. Commercial Solar Users. Washington, D.C.: Solar Energy Industries Association.

http://www.seia.org/research-resources/solar-means-business-2015-top-us-corporate-solar-users.

SEIA/GTM (Solar Energy Industries Association/GTM Research). 2015. U.S. Solar Market Insight: 2014 Year in Review. Boston and Washington, D.C.: GTM Research and Solar Energy Industries Association.

- 2016. U.S. Solar Market Insight: 2015 Year in Review. Boston and Washington, D.C.: GTM Research and Solar Energy Industries Association.

Wilcox, S., and W. Marion. 2008. Users Manual for TMY3 Data Sets. Golden, CO: National Renewable Energy Laboratory. NREL/TP-581-43156. http://www.nrel.gov/docs/fy08osti/43156.pdf. 